\title{
Case studies of particle formation events observed in boreal forests: implications for nucleation mechanisms
}

\author{
F. Yu ${ }^{1}$ and R. Turco ${ }^{2}$ \\ ${ }^{1}$ Atmospheric Sciences Research Center, State University of New York at Albany, 251 Fuller Road, Albany, \\ New York 12203, USA \\ ${ }^{2}$ Department of Atmospheric and Oceanic Sciences, University of California at Los Angeles, 405 Hilgard Ave, \\ Los Angeles, California 90095, USA
}

Received: 4 January 2008 - Published in Atmos. Chem. Phys. Discuss.: 19 March 2008

Revised: 30 June 2008 - Accepted: 5 September 2008 - Published: 22 October 2008

\begin{abstract}
Aerosol nucleation events observed worldwide may have significant climatic and health implications. However, the specific nucleation mechanisms remain ambiguous. Here, we report case studies of eight nucleation events observed during an intensive field campaign at a boreal forest site (Hyytiälä, Finland) in spring 2005. The present analysis is based on comprehensive kinetic simulations using an ionmediated nucleation (IMN) model in which the key physical and chemical parameters are constrained by a variety of recent measurements. Out of the 22 days of the campaign on which nucleation events were observed, eight major events were selected for detailed analysis on the basis of indications that the observed air masses were relatively homogeneous. In most of these cases, reasonable agreement is found between IMN predictions and field data for a range of variables, including critical nucleation sizes, size-dependent overcharging ratios, and the concentrations of $1.8-3 \mathrm{~nm}$ stable clusters and $3-6 \mathrm{~nm}$ particles, and their diurnal variations. The possible reasons leading to substantial differences between observation and theory in some cases are also explored. Statistically, roughly $80 \%$ of the nucleation events recorded during the Hyytiälä campaign exhibited mean size-dependent particle overcharging ratios within the range of, or exceeding, those predicted by the IMN model, suggesting that ion nucleation processes were significant during these events. The nucleation rates calculated using the IMN modeling approach are contrasted with those predicted by other theories/models, and key differences between the results are discussed. In particular, it is concluded that the ion nucleation model originally developed by Lovejoy et al. (2004) significantly under-
\end{abstract}

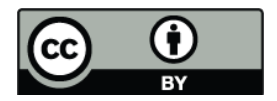

Correspondence to: $\mathrm{F}$. Yu

(yfq@asrc.cestm.albany.edu) predicts ion nucleation rates, and cannot explain the new observations from Hyytiälä regarding the electrical properties of nanoparticles. We also show that, for the well documented conditions of the Hyytiälä project, the binary and ternary homogeneous nucleation rates calculated using the most current theories would fall well below $\sim 10^{-7} \mathrm{~cm}^{-3} \mathrm{~s}^{-1}$, and thus would be negligible.

\section{Introduction}

New particle formation - regularly observed worldwide - appears to have clear spatial patterns (Kulmala et al., 2004a; Yu et al., 2008). Nevertheless, the primary mechanisms of atmospheric particle nucleation - which control aerosol number concentrations to a significant degree in many parts of the troposphere - remain elusive despite decades of intensive research. Systematic measurements of evolving air-ion mobility spectra during particle formation events, as well as of the size-resolved charged fraction (CF) of freshly formed particles, have become available recently to test nucleation theories (Vana et al., 2006; Iida et al., 2006; Hirsikko et al., 2007; Laakso et al., 2007a). The CF data adds an important constraint on the fundamental processes controlling particle production and evolution (Yu, 2006a).

An eleven-year record of continuous particle size distribution measurements at a remote boreal forest site in southern Finland reveal an annual-average of 50-100 nucleation events, with the frequency of the events peaking in springtime (Laaksonen et al., 2008). While both the long-term (three-year) record of ion mobility measurements (Hirsikko et al., 2007), and the seven-week intensive period of CF measurements for freshly nucleated particles (Laakso et al.,

Published by Copernicus Publications on behalf of the European Geosciences Union. 
2007a), taken in Hyytiälä, Finland, suggest that ions are involved in more than $90 \%$ of the particle formation events that can be clearly identified, the relative contributions of ionmediated nucleation versus neutral processes remains controversial (Laakso et al., 2007a; Kulmala et al., 2007; Yu and Turco, 2007; Yu et al., 2008). An analysis of these measurements by Laakso et al. (2007a) concluded that ion nucleation processes make a relatively small contribution to new particle formation (under the conditions sampled). However, when Yu and Turco (2007) applied a different analytical methodology to the same data, they found significant contributions from ion-mediated nucleation (IMN). These differences have never been resolved. More recently, Kulmala et al. (2007) concluded that neutral nucleation dominates over ion-induced nucleation at least in boreal forest conditions, based on their analysis of four days of multiple-instrument measurements of neutral and charged nanometer-sized cluster concentrations obtained in Hyytiälä, Finland in spring 2006. Again, Yu et al. (2008), in their replies to referee's comments published in Atmos. Chem. Phys. Diss., reanalyzed the observations and emphasized that a substantial contribution from ion-mediated nucleation could not be ruled out based on the data reported in Kulmala et al. (2007).

Apparently, different interpretations of field observations of "nucleation" events have created ambiguity with regard to the relative importance of ion versus neutral nucleation processes, even when the same set of measurements are considered. To resolve the conflicting conclusions with regard to the importance of IMN, we focus here on recent data from the boreal forest experiments noted above, which obtained the most extensive set of relevant parameters to date. If these events can be explained in the context of a self-consistent theory, then the underlying nucleation mechanisms can be clarified. Further, if an articulated mechanism can be shown to reproduce nucleation events for the range of conditions encountered in a boreal forest setting, more reliable predictions of global-scale nucleation rates will be within reach (e.g., Yu et al., 2008). On the other hand, if the IMN mechanism cannot explain such observations, then the search should be refocused to identify the nucleation processes behind the observed particle formation events, inasmuch as none of the existing theories for binary or ternary homogeneous nucleation provide a quantitative explanation for most of these observations.

The main objective of this work, therefore, is to carry out detailed case studies of boreal forest nucleation events to investigate the competitive nucleation processes represented in the IMN model (that is, the ion and neutral binary system processes that are currently quantifiable). By constraining the key parameters in these simulations using observations, we aim to: (1) test the ability of the current IMN model to account for the observed concentrations of freshly nucleated particles in the 3-6 $\mathrm{nm}$ size range; (2) assess the consistency of observed charged fractions of freshly nucleated particles against IMN model predictions under sampled condi- tions; and (3) compare nucleation rates predicted by the IMN model with those based on other existing nucleation models/parameterizations to highlight differences between various approaches, and to determine which of these representations are viable in light of the new data from Hyytiälä.

\section{The kinetic IMN model and data sources for case studies}

\subsection{Kinetic IMN model}

The IMN model (Yu and Turco, 1997, 2000, 2001) simulates ion mass spectra and nanoparticle electrical charge fractions by explicitly resolving the non-linear size-dependent microphysical interactions among precursor gases, positively charged, negatively charged and neutral clusters, and particles ranging from small molecular aggregates to several micrometers in diameter. An earlier version of the IMN model has been extended by incorporating new thermodynamic data and physical algorithms (Yu, 2006a). Yu (2007) has further improved the model by employing two independent measurements to constrain monomer hydration in the $\mathrm{H}_{2} \mathrm{SO}_{4}-\mathrm{H}_{2} \mathrm{O}$ system (Marti et al., 1997; Hanson and Eisele, 2000), and by incorporating the energetics of small neutral $\mathrm{H}_{2} \mathrm{SO}_{4}-\mathrm{H}_{2} \mathrm{O}$ clusters determined by Hanson and Lovejoy (2006) and Kazil et al. (2007). In the atmosphere, nanoparticle nucleation and growth are fully coupled, and in many situations organic species dominate the growth of freshly formed particles. The present version of the IMN model considers the cocondensation of sulfuric acid and organic compounds upon activated particles (Yu, 2006a), although there is substantial uncertainty regarding the abundances of organic precursors and their actual role in the nucleation process. A detailed description of the present treatments of physics and thermodynamics in the IMN model is given by Yu (2006a).

\subsection{Selection of case study days}

The long-term and multiple-instrument characterizations of nucleation events obtained by Kulmala and colleagues in Hyytiälä, Finland are clearly unique, and provide the most comprehensive and detailed set of data available so far to test atmospheric nucleation theories. Of greatest significance is the determination of the electrical charge fraction (CF) of the nanometer-sized particles as they evolve during nucleation bursts (Laakso et al., 2007a). The CF data provide an unambiguous signal of ion nucleation when the observed CFs exceed the equilibrium charge fractions characteristic of the ambient aerosol. Measured CFs are typically given relative to the ambient $\mathrm{CF}$, at each size, in terms of the overcharge ratio (OR). For a system in equilibrium with the background ion plasma, $\mathrm{OR} \sim 1$. However, when ions represent a substantial fraction of the nuclei for particle formation, OR values greatly exceeding 1 can be achieved. Conversely, when 
neutral (homogeneous) nucleation is dominant, and ion contributions are small or negligible, OR values in the nanoparticle size range will typically be $<\sim 1$ (an undercharged state). Homogeneous nucleation events generate high concentrations of small neutral particles that strongly drive the OR downward. Even so, in all cases, OR values tend to adjust rapidly toward the equilibrium state (i.e., $\mathrm{OR} \simeq 1$ ) at all sizes as the aerosol evolves. It follows that any analysis of nucleation events for which CF (or OR) data are available should involve a comprehensive treatment of the charging and discharging processes of nanometer particles. Hence, a study of the Hyytiälä measurements that includes these details is more likely to shed light on the formation mechanisms of atmospheric aerosols.

We have carried out case studies of nucleation events observed during spring 2005 (day 95-day 136, corresponding to 5 April-16 May) in Hyytiälä, during the BACCI/QUEST IV intensive field campaign (Laakso et al., 2007a; Riipinen et al., 2007). Among the 42 days of this field campaign, Riipinen et al. (2007) identified 22 days as nucleation event days. From these 22 event days, we selected 8 days (days \# $102,103,108,117,122,123,132$, and 136) for the present case studies, using indications that the sampled air masses were relatively homogeneous. Air mass homogeneity was judged on the basis of relatively consistent and continuous changes in the measured concentrations of the key precursor gas $\mathrm{H}_{2} \mathrm{SO}_{4}\left(\left[\mathrm{H}_{2} \mathrm{SO}_{4}\right]\right)$, and the abundances of freshly nucleated particles in the $3-6 \mathrm{~nm}$ size range $\left(\mathrm{N}_{3-6}\right)$. It should be emphasized that air mass homogeneity is essential for meaningful point-site data analysis, while heterogeneity in a data record presents severe problems in interpreting timeintegrative transient events such as nucleation bursts. For one thing, the temporal variations in the observed parameters become a strong function of the spatial variability and air mass velocity, masking the actual underlying behavior. Moreover, changes in key integrative variables - such as $\mathrm{H}_{2} \mathrm{SO}_{4}$ concentrations and condensation sinks - in any specific air parcel cannot be reliably reconstructed over the time span of many hours required for nucleation and growth of the embedded aerosols.

Here, when we discuss air mass variability, we refer to the local inhomogeneity in an air mass. As far as nucleation is concerned, local air mass inhomogeneity can be clearly seen as rapid and otherwise unattributable fluctuations in measured $\left[\mathrm{H}_{2} \mathrm{SO}_{4}\right], \mathrm{N}_{3-6}$, and/or particle size distributions. Airborne measurements of nucleation-mode aerosol concentrations during nucleation events over boreal forests, for example, reveal significant variability in nucleated particle concentrations attributable to variability in land coverage between forests and lakes (O'Dowd et al., 2008). It is clear from Fig. 1b of Riipinen et al. (2007) that the days selected for the present case studies are the most uniform and complete in terms of the $\left[\mathrm{H}_{2} \mathrm{SO}_{4}\right]$ and $\mathrm{N}_{3-6}$ data records, although some level of inhomogeneity obviously remains. Other nucleation days were not selected because of either in- completeness in the $\left[\mathrm{H}_{2} \mathrm{SO}_{4}\right]$ and/or $\mathrm{N}_{3-6}$ time series, or relatively large scatter in the data (particularly in earlier morning and noontime periods).

Based on the average overcharge ratios reported by Laakso et al. (2007a), it appears that freshly nucleated particles were relatively highly overcharged on five of the selected case study days (18 April, 27 April, 3 May, 12 May and 16 May), weakly overcharged on one day (13 April), and clearly undercharged on one day (2 May). Overcharging data were not available for 12 April. According to both the 7-week ionDMPS data shown in Laakso et al. (2007a) and one year of ion-DMPS data summarized by Gagné et al. (2008), a large fraction $(\sim 80 \%)$ of nucleation event days observed in boreal forests exhibits clear overcharging of the $3-5 \mathrm{~nm}$ particles. Thus, the eight case study days, originally selected on the basis of their relative homogeneity, are also representative in term of the charging state of the freshly nucleated particles. It should be noted that the charge fraction data are presented as average values over certain periods of an event. Presumably, this is done to reduce the high variability inherent in the $\mathrm{CF}$ measurements. For a homogeneous air mass, such averaging of the CFs should yield the characteristic global charging state of the nucleated aerosols. However, in a highly heterogeneous air mass, segments of data may correspond to quite different nucleation events and/or processes, and the average $\mathrm{CF}$ values may include periods with overcharging and undercharging. Hence, appropriate caution must be used in interpreting simulations for these days.

In summary, the selected case study days are reasonably representative of the ranges of $\left[\mathrm{H}_{2} \mathrm{SO}_{4}\right]$ and $\mathrm{N}_{3-6}$ observed during the BACCI/Quest IV field campaign (Riipinen et al., 2007), as well as of the charged fractions (CFs) of $3 \mathrm{~nm}$ particles (Laakso et al., 2007a). In this work, we also assumed a constant background ionization rate of 5 ion-pairs $\mathrm{cm}^{-3} \mathrm{~s}^{-1}$, consistent with the typical ionization rates derived from measurements in the region of interest (Laakso et al., 2004a).

\subsection{Time series of sulfuric acid vapor concentrations}

As noted above, in order to constrain the model simulations, it is desirable to have a time series of key precursor gases (i.e., $\mathrm{H}_{2} \mathrm{SO}_{4}$ and condensable organics), temperatures, relative humidity, and condensation sinks (or size distributions of pre-existing particles) within specific air parcels. Such Lagrangian data are not available, since all the measurements under consideration were collected at stationary field sites. Accordingly, the selection of data sets based on air mass homogeneity provides the most reasonable alternative. Current theory indicates that sulfuric acid vapor is the critical species controlling nucleation at the sites of interest (e.g., Riipinen et al., 2007). Figure 1 shows the time series of observed $\mathrm{H}_{2} \mathrm{SO}_{4}$ concentrations $\left(\left[\mathrm{H}_{2} \mathrm{SO}_{4}\right]\right)$ on the eight selected days investigated here. The data points are from Fig. $1 \mathrm{~b}$ of $\mathrm{Ri}-$ ipinen et al. (2007). The smaller fluctuations in the data are likely associated with local inhomogeneities in the air masses 

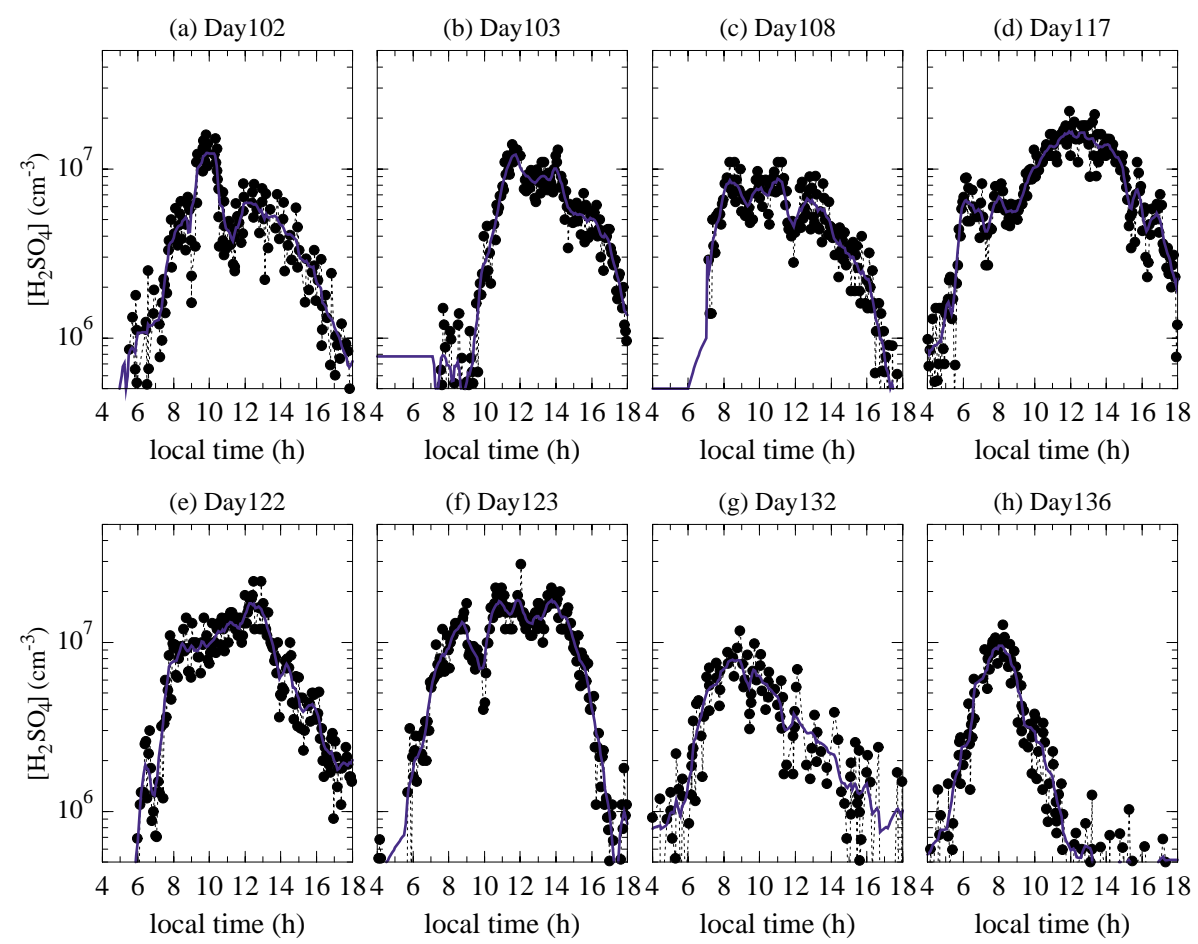

Fig. 1. Time series of observed $\mathrm{H}_{2} \mathrm{SO}_{4}$ concentrations for the eight case study days. The data points are taken from Fig. 1b of Riipinen et al. (2007). Fluctuations in the data are likely to be associated with inhomogeneities in the air masses sampled at the fixed field site. Such Eulerian, as opposed to Lagrangian, sampling introduces an irreducible uncertainty into the analysis since the history of any particular simulated air parcel must be reconstructed using the observations from continually changing air masses (also see the discussion in the text). In the present simulations, each $\left[\mathrm{H}_{2} \mathrm{SO}_{4}\right]$ time series has been smoothed using an 9-point running average, which is shown as a solid blue curve.

sampled. In our simulations, we use smoothed (9-point running average) $\left[\mathrm{H}_{2} \mathrm{SO}_{4}\right]$ time series, given by the solid blue curves in the figure. The smoothing has little impact on the simulation outcomes.

\subsection{Condensable organic species}

Compared to sulfuric acid vapor, which is often directly measured, condensable organic species (COS) are only poorly characterized. Certain organic compounds are known to contribute to, or even dominate, the growth of nucleated particles. Laaksonen et al. (2008) showed that particle growth rates during many boreal forest nucleation events are correlated with the gas phase concentrations of monoterpene oxidation products (MTOPs). However, both Janson et al. (2001) and Sellegri et al. (2005a) concluded that, based on measurements made during two different boreal forest field campaigns (BIOFOR and QUEST), the oxidation products of terpenes were not the primary nucleating species observed at Hyytiälä. The main reasons leading to this conclusion include: (1) that the concentrations of the terpenes and their oxidation products where higher at night when no nucleation was observed (Janson et al., 2001; Sellegri et al, 2005a); (2) that organic oxidation products were not significantly ele- vated during event days compared to non-event days based on the results from the BIOFOR campaign (Janson et al., 2001); and (3) that organic compounds including terpenes are generally lower during event days compared to non-event days based on QUEST data (Sellegri et al, 2005a).

In this study, the diurnal variations of the overall COS concentration $\left.\left(C_{\mathrm{COS}}\right)\right)$ is parameterized to follow that of the averaged and smoothed curve of MTOP, as shown in Fig. $6 \mathrm{~b}$ of Sellegri et al. (2005b). That curve yields a peak concentration around midnight and a minimum concentration in the early afternoon, with a ratio of maximum to minimum values of around 2.3. Due to the lack of information about the saturation vapor pressures of the condensable organics, we assume that COS only condenses on particles larger than a certain activation size $\left(D_{\text {act }}\right)$. For the present purposes, the baseline value of $D_{\text {act }}$ is taken to be $3 \mathrm{~nm}$, which is within the range estimated by Kulmala et al. $(2004 b$, c). As we will show below (Sect. 3.1), $D_{\text {act }}$ of $\sim 3 \mathrm{~nm}$ appears to be reasonable based on the time delay between the increase in $\left[\mathrm{H}_{2} \mathrm{SO}_{4}\right]$ and $\mathrm{N}_{3-6}$ in early morning. The COS molecules are assigned an average molecular weight of $180 \mathrm{~g} / \mathrm{mol}$ and a density of $1.5 \mathrm{~g} \mathrm{~cm}^{-3}$ (Engelhart et al., 2008). In this study, unless specified, we assume a peak COS concentration 
$\left(\mathrm{C}_{\mathrm{COS}}^{\text {peak }}\right)$ of $6 \times 10^{7} / \mathrm{cm}^{3}$ that, combined with $\left[\mathrm{H}_{2} \mathrm{SO}_{4}\right]$, results in growth rates of nucleated particles of $\sim 1-5 \mathrm{~nm} / \mathrm{hr}$, which are generally consistent with observations in boreal forests (Kulmala et al., 2004b; Riipinen et al., 2007; Laaksonen et al., 2008). In the real atmosphere, different organic compounds are likely to be involved in nucleation and growth processes, and the concentration time series of these species - and corresponding $D_{\text {act }}$ - may differ from the average values adopted here. The uncertainties in COS concentrations, specific molecular properties, and $\mathrm{D}_{\text {act }}$ lead to uncertainties in the simulated concentrations and size distributions of freshly nucleated particles and their overcharging ratio, but should not have significant impacts on predicted nucleation rates as long as these species are not directly involved in the nucleation phase itself.

\subsection{Temperature and relative humidity}

The time variations in temperature (T) and relative humidity $(\mathrm{RH})$ used to constrain the simulations are illustrated in Fig. 2. In the ACPD version of this paper, the $\mathrm{T}$ and $\mathrm{RH}$ data were averaged from two weather stations close to Hyytiälä: one in Jyväskilä (about $80 \mathrm{~km}$ northeast of Hyytiälä) and the other in Tampere (about $40 \mathrm{~km}$ southwest of Hyytiälä). During the revision of this paper, we secured access to the $\mathrm{T}$ and RH data measured in Hyytiälä (L. Laakso, personal communication). A comparison of the data indicates that the $\mathrm{T}$ and RH values averaged from the two weather stations (Jyväskilä and Tampere) are generally representative of those measured in Hyytiälä. The T and RH data in Fig. 2 should represent the corresponding meteorological conditions in the broader Hyytiälä area where the regional nucleation events occurred.

2.6 Size distributions of pre-existing particles and condensation sink

Pre-existing particles affect nucleation by scavenging sulfuric acid vapor and freshly nucleated molecular clusters. The condensation sink (CS) due to pre-existing particles typically ranged from $0.5 \times 10^{-3}-3.5 \times 10^{-3} \mathrm{~s}^{-1}$ during the spring nucleation events observed in Hyytiälä, and generally exceeded $6 \times 10^{-3} \mathrm{~s}^{-1}$ during non-events (Laakso et al., 2004b; Sellegri et al., 2005; Dal Maso et al., 2005). Due to the changing air masses, measured CS values over some nucleation event days were seen to fluctuate significantly (Laakso et al., 2004b; Sellegri et al., 2005b). In the present analysis, the initialization of the size distributions for pre-existing particles was guided by the measured particle size distributions (or log-normal mode fitting parameters for Aitken and accumulation modes) during the nucleation periods (L. Laakso, personal communication; Ehn et al., 2007). Based on the measured particle size distributions (e.g., Ehn et al., 2007), significant variations in the sampled air masses occur frequently during the early morning hours in Hyytiälä. The present simulations start at 04:00 a.m., whereas the observed
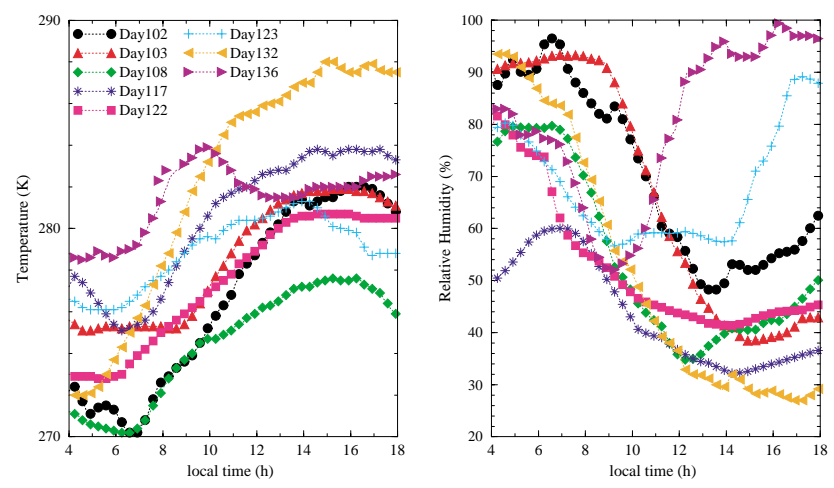

Fig. 2. The time series of temperature (T) and relative humidity (RH) used to constrain the simulations for the eight case studies. Refer to the text for details.

log-normal mode parameters (total number concentrations, mean mode sizes, and standard deviations) recorded around 11:00 a.m. are used to constrain the size distributions of preexisting particles in the model. To investigate the effect of CS variations and uncertainties on the simulated results, appropriate sensitivity studies are considered below.

\section{Detailed case studies and results}

\subsection{Time series of the concentrations of freshly nucleated} particles

Figure 3 shows the simulated (dashed lines) and observed (lines with symbols) time-dependent variations of particles in the 3-6 nm range $\left(\mathrm{N}_{3-6}\right)$ for the eight selected nucleation event days. To facilitate the discussion, we also plot the time series of $\left[\mathrm{H}_{2} \mathrm{SO}_{4}\right]$ used in the simulations (solid blue lines, plus one green line in panel Fig. $3 \mathrm{c}$ representing a specific sensitivity study). The observed $\mathrm{N}_{3-6}$ time series are taken from Fig. 1b of Riipinen et al. (2007), with a "time shift" correction, as described below. Due to a plotting problem, the $\mathrm{N}_{3-6}$ time series shown in the published version of Fig. $1 \mathrm{~b}$ of Riipinen et al. (2007) was inadvertently "compressed" in such a way that the $\mathrm{N}_{3-6}$ data is shifted toward earlier times by an interval that ranges from 0 to $\sim 2 \mathrm{~h}$ in moving from the leftmost to rightmost times in the figure (L. Laakso, personal communication). Through discussions with the authors, we have been able to compensate for the time-scale compression in re-plotting the $\mathrm{N}_{3-6}$ time series data in Fig. 3.

It should be noted again that the measurements were obtained at a fixed site in constantly changing air masses, while the simulations essentially follow an air parcel assumed to be embedded within a homogeneous regional air mass. The comparisons with measurements are therefore meaningful only when the air mass upwind of the measurement site(s) is spatially relatively uniform. As explained earlier, the consistency in measurements of variations in key parameters, 

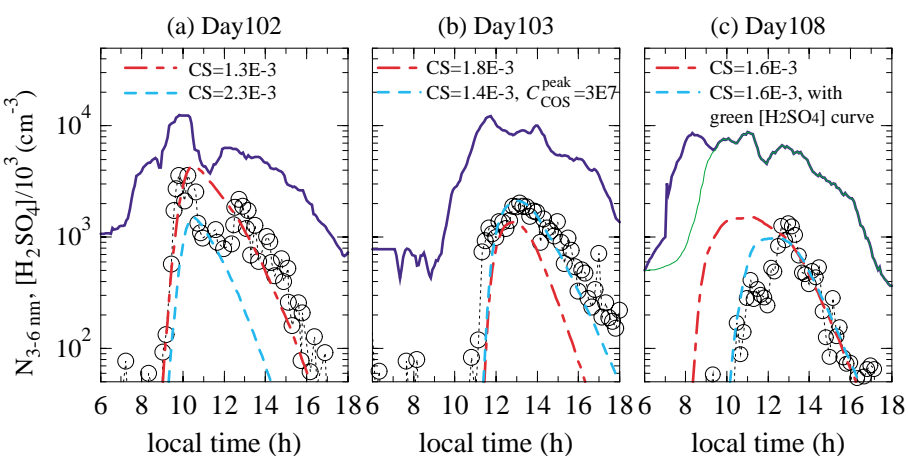

(d) Day117
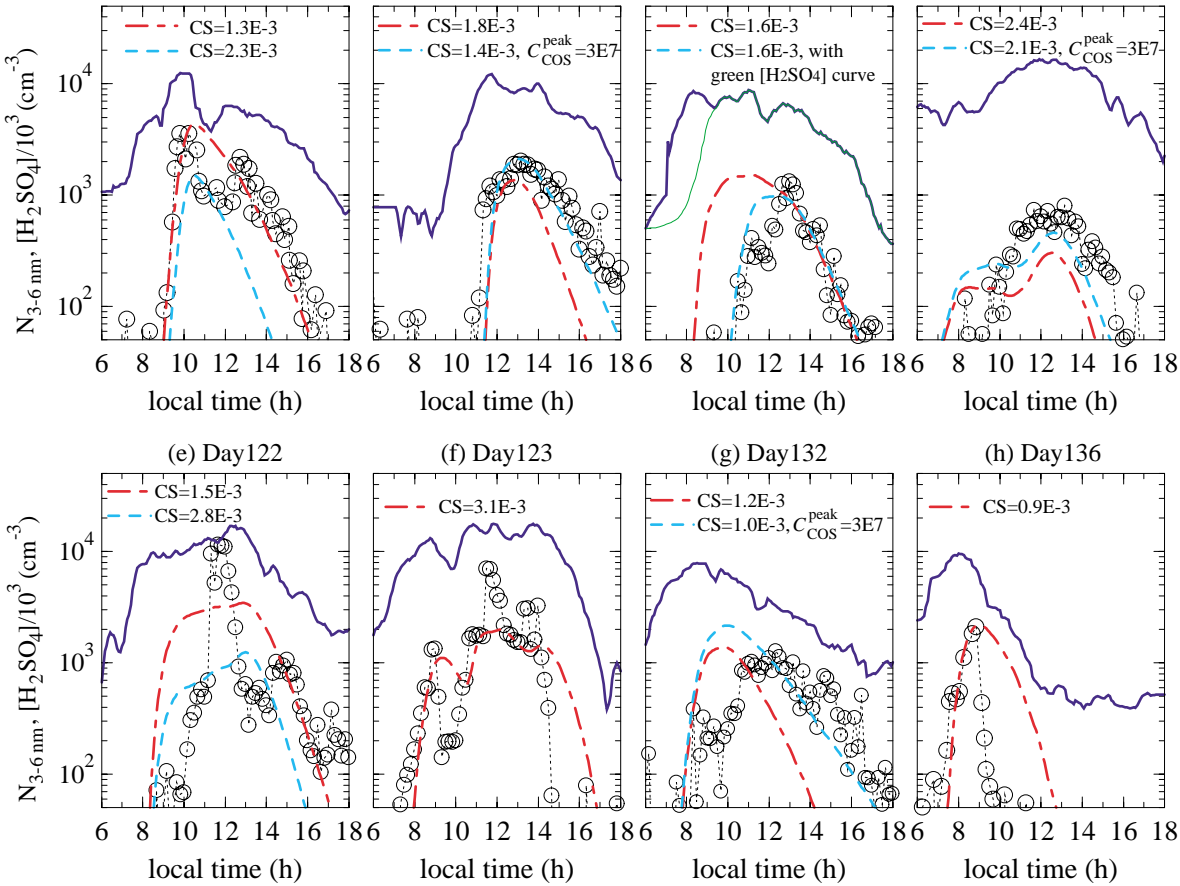

Fig. 3. Time-dependent variations in the concentrations of particles in the size range $3-6 \mathrm{~nm}\left(\mathrm{~N}_{3}-6\right)$ corresponding to the eight case study days. The data of Riipinen et al. (2007) are given as open circles in each panel; the $\left[\mathrm{H}_{2} \mathrm{SO}_{4}\right]$ time series from Fig. 1 (scaled by a factor of 1000) are reproduced as solid blue curves. The model simulations are shown as dashed lines, where the corresponding average values of the condensation sink (CS) over the nucleation/growth period in each case are indicated in the panel legends $\left(\mathrm{read} 1.25 \mathrm{E}-3\right.$ as $1.25 \times 10^{-3} \mathrm{~s}^{-1}$ ). The green line in panel $3 \mathbf{c}$ indicates the modified $\left[\mathrm{H}_{2} \mathrm{SO}_{4}\right]$ time series used as a sensitivity test. In panels $3 \mathbf{b}$, $\mathbf{d}$, and $\mathbf{g}$, a dashed cyan line

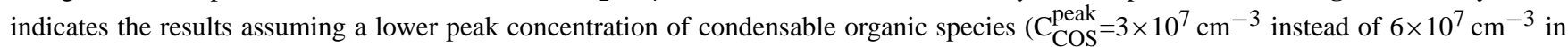
the other cases). In panels $3 \mathbf{a}$ and $\mathbf{e}$, the dashed cyan curve shows the results corresponding to a higher condensation sink. See text for details.

such as $\left[\mathrm{H}_{2} \mathrm{SO}_{4}\right]$ and $\mathrm{N}_{3-6}$, is used as an indication of the level of homogeneity in the sampled air masses, and data records were selected for the present case studies that exhibit reasonable consistency in this sense. Nevertheless, even on carefully selected days, some degree of heterogeneity among the sampled air mass is unavoidable, and the measured concentrations of precursor gases and pre-existing particles (and hence CS) can still fluctuate substantially (Ehn et al., 2007; also see Fig. 1). The CS values given in the legends to Fig. 3 are averaged values over the main nucleation and growth period (for which $\mathrm{J}_{3 \mathrm{~nm}}>0.01 \mathrm{~cm}^{-3} \mathrm{~s}^{-1}$ ).

In addition, the assumed time series of $\mathrm{C}_{\mathrm{COS}}$ (based on the average results given in Sellegri et al., 2005b) may be quite different from actual concentrations on certain days. To explore the impact of these uncertainties on the apparent particle formation rates, a number of sensitivity studies were carried out; these results are presented as the dashed cyan curves in Fig. 3a-e, and 3g.

Overall, the model-predicted time series (or diurnal variations) for $\mathrm{N}_{3-6}$ agree reasonably well with those measured on most of the selected case study days, although differences exist in the details, as discussed below.
The ion-mediated nucleation (IMN) model appears to capture the timing and rapid increase in $\mathrm{N}_{3-6}$ in the early morning hours on days 102,103,123,132 and 136 as well as the particle concentration. The time delay $(\sim 1.5-2 \mathrm{~h})$ between the increase in $\left[\mathrm{H}_{2} \mathrm{SO}_{4}\right]$ and $\mathrm{N}_{3-6}$ is consistent with a mean growth rate of about $1 \mathrm{~nm} / \mathrm{hr}$ for sub- $3 \mathrm{~nm}$ particles, as is frequently observed in boreal forests (Kulmala et al., $2004 \mathrm{~b})$. It should be noted that, due to variations in $\left[\mathrm{H}_{2} \mathrm{SO}_{4}\right]$, the growth rates of sub- $3 \mathrm{~nm}$ particles change with time, and the appearance of particles larger than $3 \mathrm{~nm}$ is the cumulative (or integral) result of cluster dynamics occurring over the past one or more hours. Such an integral process is explicitly simulated in the kinetic IMN model. In the present simulations, only $\mathrm{H}_{2} \mathrm{SO}_{4}$ and $\mathrm{H}_{2} \mathrm{O}$ are assumed to contribute to the formation and growth of particles smaller than $3 \mathrm{~nm}$, while organics condense only on particles larger than $3 \mathrm{~nm}$ (i.e., $D_{\text {act }}=3 \mathrm{~nm}$ ). The favorable agreement in the timing of rapid morning increase in $\mathrm{N}_{3-6}$ for the five case study days indicates that $\mathrm{H}_{2} \mathrm{SO}_{4}$ and $\mathrm{H}_{2} \mathrm{O}$ can fully account for the initial formation and growth of new particles, and thus our assumed $D_{\text {act }}$ of $\sim 3 \mathrm{~nm}$ seems to be reasonable. A smaller $D_{\text {act }}$ would increase the growth rate of sub- $3 \mathrm{~nm}$ particles, shift 
the simulated increase in $\mathrm{N}_{3-6}$ toward the left (earlier times), and hence degrade the agreement.

For the remaining three case study days (days 108, 117, 122), the predicted increases in $\mathrm{N}_{3-6}$ precede those observed by $\sim 1-2 \mathrm{~h}$. On these three days, the time delay between the observed increase in $\left[\mathrm{H}_{2} \mathrm{SO}_{4}\right]$ and $\mathrm{N}_{3-6}$ is exceptionally long ( $\sim 3-4$ h), which seems physically inconsistent with the expected growth rates of sub-3 nm particles even with sulfuric acid condensation alone. It is possible that the apparent delayed onset of particle formation on these days (longer than the typical $\sim 1.5 \mathrm{~h}$ delay) is associated with the variability in the air masses sampled during the morning hours, when such variability can be significant. For example, the air masses sampled during the main nucleation periods $(\sim 10$ a.m. and after) on these days may have actually experienced quite different $\left[\mathrm{H}_{2} \mathrm{SO}_{4}\right]$ time series than those recorded in the early morning hours due to a substantial shift in air mass composition (e.g., refer to Fig. 3a of Riipinen et al., 2007). To illustrate how a somewhat different $\left[\mathrm{H}_{2} \mathrm{SO}_{4}\right]$ time series might affect the timing of the $\mathrm{N}_{3-6}$ increase, we carried out the sensitivity study presented in Fig. 3c, where the green curve shows a modified $\left[\mathrm{H}_{2} \mathrm{SO}_{4}\right]$ time series while the dashed cyan curve gives the corresponding predicted $\mathrm{N}_{3-6}$. As expected, a delay in the increase in $\left[\mathrm{H}_{2} \mathrm{SO}_{4}\right]$ in the early morning brings the predicted $\mathrm{N}_{3-6}$ closer to the observations. The high sensitivity of the apparent particle formation rates to recent air mass history reinforces the idea that it is critical to identify homogeneous air masses if meaningful model-observational comparisons are to be carried out.

The slower decrease in $\mathrm{N}_{3-6}$ during the afternoon is also generally reproduced by the model, with the exception of the days 103 and 132 (refer to the red dashed lines in Fig. 3b and g), when the model recovery occurred more rapidly than that observed. Since $\mathrm{dN}_{3-6} / \mathrm{dt}$ depends not only on the formation rates of $3 \mathrm{~nm}$ particles but also on the growth rate of 3-6 nm particles (i.e., the rate at which particles are growing out of the 6-nm size range) (Riipinen et al., 2007), we may have significantly overestimated the concentrations of condensable organic species during the afternoons on these days, and hence the 3-6 $\mathrm{nm}$ particle growth rates. Sensitivity studies given in Figs. $3 \mathrm{~b}$ and g clearly show improved agreement (cyan dashed lines) when a lower $\mathrm{C}_{\mathrm{COS}}$ (peak values $3 \times 10^{7} \mathrm{~cm}^{-3}$ ) and somewhat reduced CS value are assumed. On day 136 , the observed $\mathrm{N}_{3-6}$ decreases suddenly around 09:00 a.m., which is probably associated with a rainfall occurring around that time (based on meteorological records archived in www.wunderground.com). The simulated $\mathrm{N}_{3-6}$ on day 136 drops gradually after 09:00 a.m. because particle washout was not considered in these simulations.

During certain periods on days 122, 123, and 132, the data fluctuates substantially, which again is likely to be associated with inhomogeneities in the air masses sampled at those times. In some cases, the fluctuations appear to be correlated with changes in key factors, such as $\left[\mathrm{H}_{2} \mathrm{SO}_{4}\right]$. For example, the air mass sampled between 09:00-10:00 a.m. on day
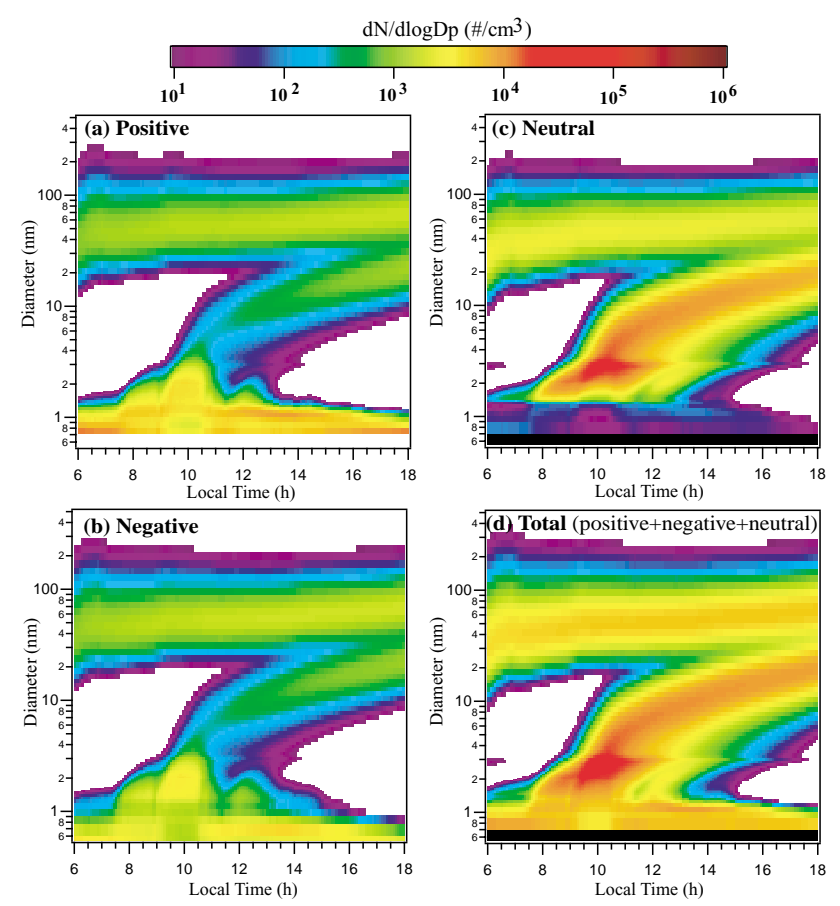

Fig. 4. Simulated evolution of particle size distributions $\left(\mathrm{d} N / \mathrm{d} \log D_{p}\right.$ ) for various particle types corresponding to the case study on 12 April 2005 (day 102): (a) - positively charged; (b) negatively charged; (c) - neutral; and (d) - total. Black color is used for $\mathrm{d} N / d \log D_{\mathrm{p}}$ value above the scale $\left(>10^{6} \mathrm{~cm}^{-3}\right) . \mathrm{CS}=1.3 \times 10^{-3}$ $\mathrm{s}^{-1}, \mathrm{C}_{\mathrm{COS}}^{\text {peak }}=6 \times 10^{7} \mathrm{~cm}^{-3}$. Refer to the text for details.

123 reveals a sudden dip in $\left[\mathrm{H}_{2} \mathrm{SO}_{4}\right]$ (also refer to Fig. 1f) that suggests a rapidly changing air mass composition. Such anomalous air masses may represent a localized plume, or some other non-regional perturbation. Using time-smoothed $\left[\mathrm{H}_{2} \mathrm{SO}_{4}\right]$ data, the model still produces a double-peaked response in the 3-6 nm particle concentration, but of a much smaller magnitude.

Based on the size distribution evolution reported by Ehn et al. (2007) for day 122 (2 May), the air mass sampled between $\sim 11: 00$ a.m. to 02:00 p.m. appears to have quite different properties (for example, higher CS). Our simulations did show that a higher CS gives a better agreement with observed $\mathrm{N}_{3-6}$ around noon time, while a lower CS predicts improved agreement between simulated and observed $\mathrm{N}_{3-6}$ in late afternoon. Nevertheless, the model cannot reproduce the observed sudden and dramatic increase in $\mathrm{N}_{3-6}$ around 11 a.m. The cause of this anomaly in observed $\mathrm{N}_{3-6}$ remains unresolved. Such behavior may result from the sampling of air masses with very different properties (for example, time series of $\left.\left[\mathrm{H}_{2} \mathrm{SO}_{4}\right]\right)$. However, it is also possible that species other than sulfuric acid are playing a key role in the nucleation and growth of sub- $3 \mathrm{~nm}$ particles in these cases. Obviously, such species, and the corresponding physical processes involved, remain to be identified. 


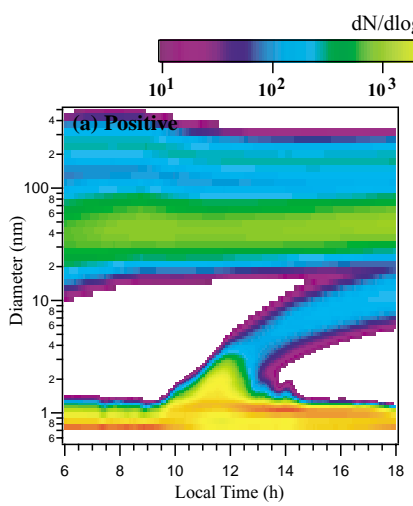

$\mathrm{N} / \mathrm{d} \log \mathrm{Dp}\left(\# / \mathrm{cm}^{3}\right)$
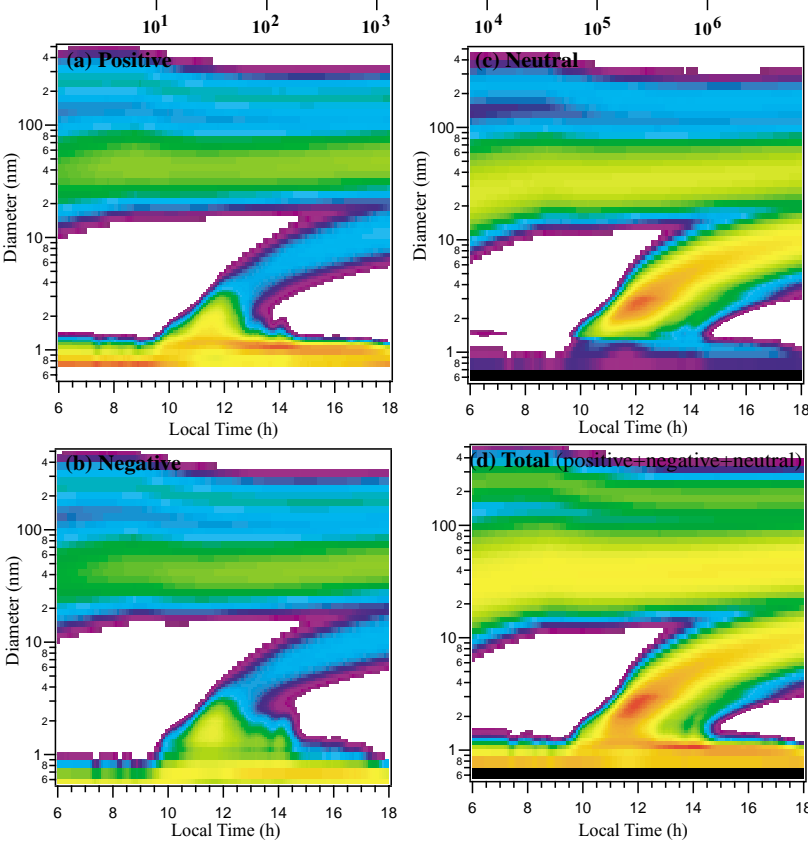

Fig. 5. Same as Fig. 4, except for the case study on 13 April 2005 (day 103). $\mathrm{CS}=1.8 \times 10^{-3} \mathrm{~s}^{-1}, \mathrm{C}_{\mathrm{COS}}^{\text {peak }}=6 \times 10^{7} \mathrm{~cm}^{-3}$.

In summary, the IMN model appears to provide a consistent representation of the observed nucleation events on most of selected case study days, considering the nature of the present model-data comparisons. To our knowledge, no other physically-based nucleation models have demonstrated a comparable capability.

3.2 Evolution of the pre-nucleation clusters and particle size distributions

Figures 4-9 show the evolution of the simulated particle size distributions for particles in several different categories during the six of eight case study days. The key parameters used to constrain the simulations are described in Sect. 2, while parameters different from baseline values are specified in the figure captions. The CS values given in the figure captions are averaged values over the main nucleation and growth period (also see Fig. 3). Under the observed atmospheric conditions, ion-mediated nucleation occurs on all eight case study days. The minimum in the evolving size distributions of charged clusters/particles in the size range of 4-6 nm during all eight nucleation events (Figs. 4-9a and $4-9 b$ ) is mainly a result of neutralization of those particles nucleated on ions, later offset by an enhancement in charging associated with increasing particle size and the absorption of ambient charge toward achieving equilibrium (Yu, 2006a). The condensation of organic species on freshly nucleated particles also contributes to the minimum around $3 \mathrm{~nm}$ in
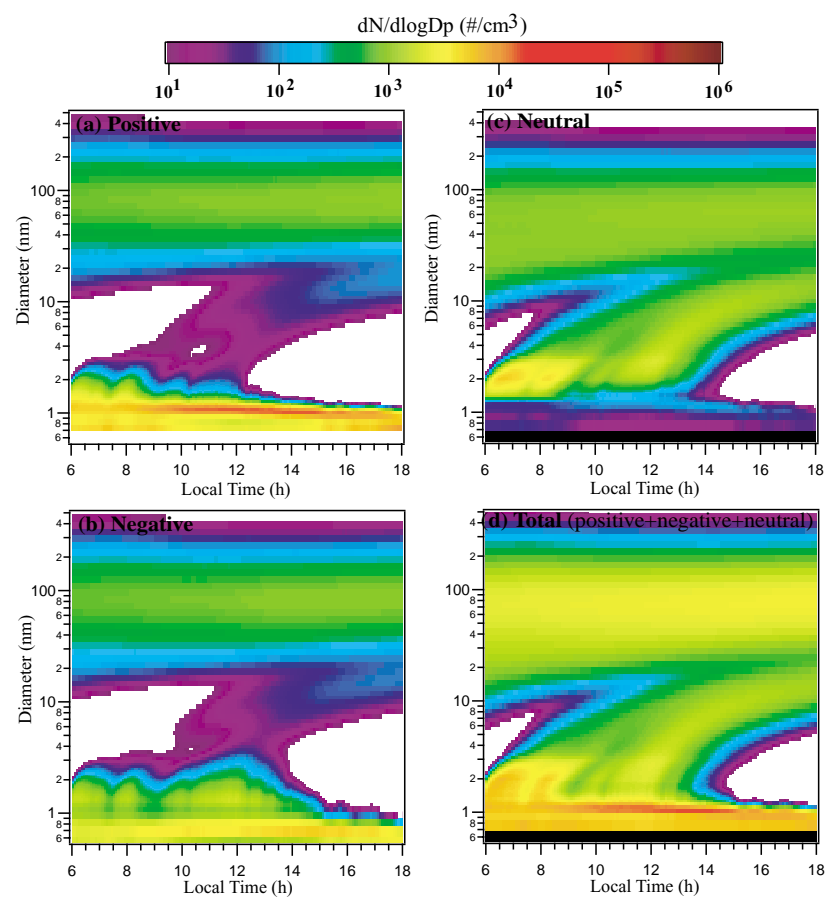

Fig. 6. Same as Fig. 4 except for the case study on 27 April 2005 (day 117). $\mathrm{CS}=2.1 \times 10^{-3} \mathrm{~s}^{-1}, \mathrm{C}_{\mathrm{COS}}^{\text {peak }}=3 \times 10^{7} \mathrm{~cm}^{-3}$.

all of the size distributions. Additionally, a gap occurs in the size range between neutral sulfuric acid monomers (diameter around $0.6 \mathrm{~nm}$ ) and neutral clusters of about $1.2 \mathrm{~nm}$ (Figs. 4-9c) due to the rapid evaporation of unstable small neutral clusters formed in this size range mainly by ion-ion recombination.

The sizes of clusters having effectively equal rates of condensation (growth) and evaporation are defined as the "critical" sizes in the kinetic IMN model (Yu, 2006a). Although the critical size for a charged cluster is smaller than that for an equivalent neutral cluster, a charged cluster that reaches its critical size should not be considered as "nucleated" until it reaches a size corresponding to the critical size of a similar neutral cluster, since if the charged cluster is neutralized before it reaches the critical neutral cluster size it may evaporate (depending, of course, on the nature of the neutralizing charged species). It should be noted that nucleation is a dynamic process and previously formed clusters, even those smaller than the critical size, can have a direct effect on the instantaneous nucleation rate. Under the conditions corresponding to the eight case studies treated here, the diameters of the critical neutral clusters predicted by the IMN model vary between $\sim 1.3 \mathrm{~nm}$ and $\sim 1.7 \mathrm{~nm}$ during periods of particle formation. These values are supported by recent measurements in boreal forests indicating that stable particle formation begins at diameters of $\sim 1.5 \mathrm{~nm}$ (Kulmala et al., 2007). 

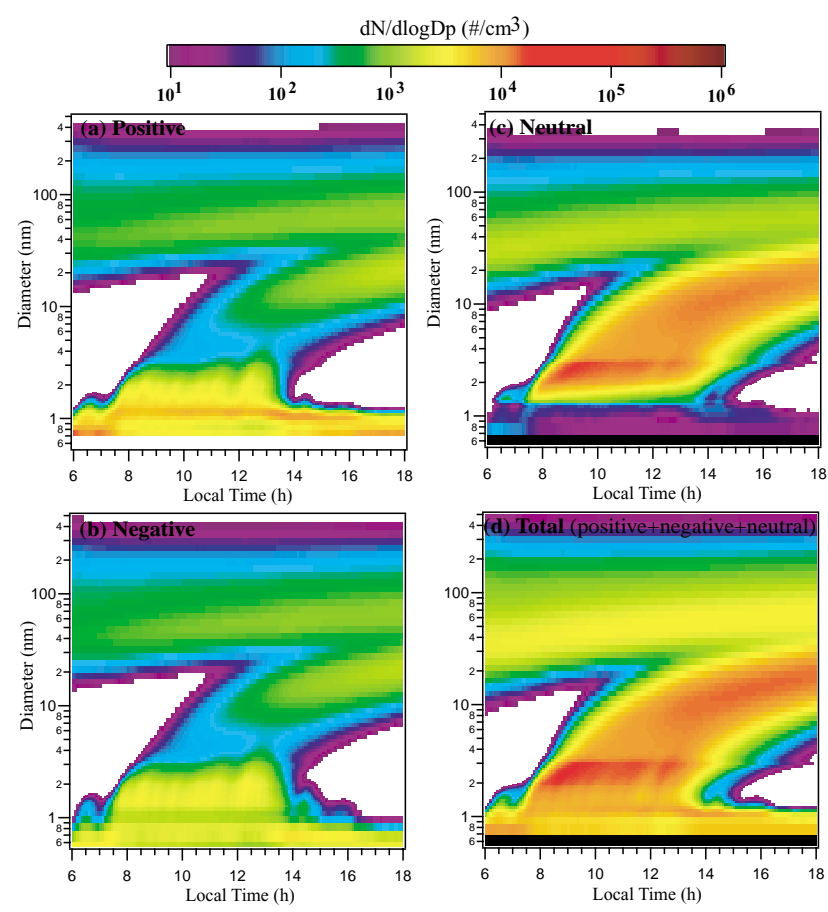

Fig. 7. Same as Fig. 4 except for the case study on 2 May 2005 (day 122). $\mathrm{CS}=1.5 \times 10^{-3} \mathrm{~s}^{-1}, \mathrm{C}_{\mathrm{COS}}^{\mathrm{peak}}=6 \times 10^{7} \mathrm{~cm}^{-3}$.

Neutral binary $\mathrm{H}_{2} \mathrm{SO}_{4}-\mathrm{H}_{2} \mathrm{O}$ clusters smaller than $\sim 1 \mathrm{~nm}$ are very unstable under the conditions corresponding to these case studies. In order for the hydrated $\mathrm{H}_{2} \mathrm{SO}_{4}$ monomer to nucleate, other species must be involved in stabling the smallest clusters. Based on the IMN theory, ions can effectively stabilize the small clusters and thus provide a channel for the formation of stable nuclei. It is possible that other species may also be able to stabilize the smaller neutral clusters. However, in order for neutral nucleation to be initiated for the conditions considered here, the stabilizing effect of these unidentified species should be at least as strong as that of an ion core. Quantum calculations of the bonding energies of hydrated $\mathrm{H}_{2} \mathrm{SO}_{4}$ monomers and dimers with ammonia and several common organic compounds (Nadykto and $\mathrm{Yu}, 2006$ ) suggest that, while such species may enhance the overall stability of hydrated $\mathrm{H}_{2} \mathrm{SO}_{4}$ dimers, the increase in stability is far less than that associated with an ion core. Accordingly, the substances commonly assumed in ternary homogeneous nucleation (THN) theories appear to be ineffective in initiating neutral nucleation under the circumstances of these case studies.

The IMN model predicts that large concentrations of neutral stable nuclei in the $1.8-3 \mathrm{~nm}$ size range are formed as nucleated ions are neutralized (Figs. 4-9c). Previously, Kulmala et al. (2000) had postulated very high background abundances of thermodynamically stable clusters (TSCs), exceeding $10^{5} / \mathrm{cm}^{3}$, produced by THN. However, as just noted, standard THN models are now known to overestimate nucleation
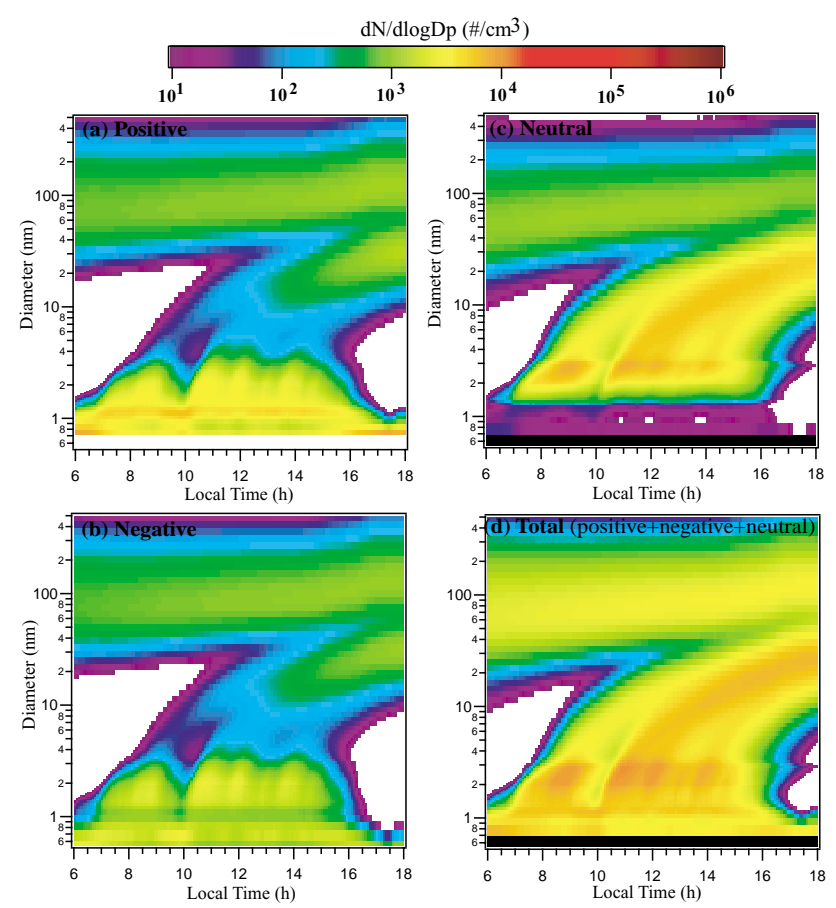

Fig. 8. Same as Fig. 4 except for the case study on 3 May 2005 (day 123). $\mathrm{CS}=3.1 \times 10^{-3} \mathrm{~s}^{-1}, \mathrm{C}_{\mathrm{COS}}^{\text {peak }}=6 \times 10^{7} \mathrm{~cm}^{-3}$.

rates substantially (Yu, 2006b). IMN, by contrast, creates TSCs as a result of natural ion processing, in which ambient ion-ion recombination acts as a potential source of TSC nuclei. As can be seen from Figs. 4-9, the TSCs (at sizes from $1.8-3 \mathrm{~nm}$ ) generated via IMN have a clear diurnal variation. The peak concentrations of $1.8-3 \mathrm{~nm}$ particles range from $\sim 1000$ to $\sim 5000 \mathrm{~cm}^{-3}$ on different days. Such concentrations are, in fact, consistent with the several thousands of $1.8-3 \mathrm{~nm}$ particles per cubic centimeter typically detected in boreal forest, as reported in Kulmala et al. (2007). A predicted strong diurnal variation in the abundance of $1.8-3 \mathrm{~nm}$ TSCs appears to be consistent with the limited NAIS-positive and UF0-02proto CPC pair data and charged clusters measured by AIS and BSMA reported in Kulmala et al.'s (2007). However, it seems to be in conflict with the NAIS-negative measurements presented in Kulmala et al. (2007). Resolution of the behavior of these stable neutral nanoparticles may have important implications for the underlying nucleation mechanism. For example, a continuous and nearly constant nucleation source must operate day and night to maintain an almost steady concentration of a few thousand $1.8-3 \mathrm{~nm}$ particles per $\mathrm{cm}^{3}$. Since kinetically the concentrations of $\mathrm{H}_{2} \mathrm{SO}_{4}$ at night $\left(\sim 5 \times 10^{5} / \mathrm{cm}^{3}\right.$ or less $)$ are far too low to produce the observed 1.8-3 nm clusters, species other than $\mathrm{H}_{2} \mathrm{SO}_{4}$, $\mathrm{H}_{2} \mathrm{O}$, and $\mathrm{NH}_{3}$ must dominate the formation of the observed $1.8-3 \mathrm{~nm}$ particles, implying a completely new (and yet to be identified) nucleation mechanism. 


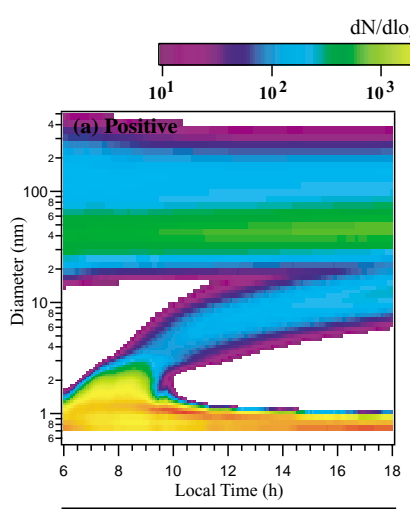

$\mathrm{N} / \mathrm{d} \log \mathrm{Dp}\left(\# / \mathrm{cm}^{3}\right)$
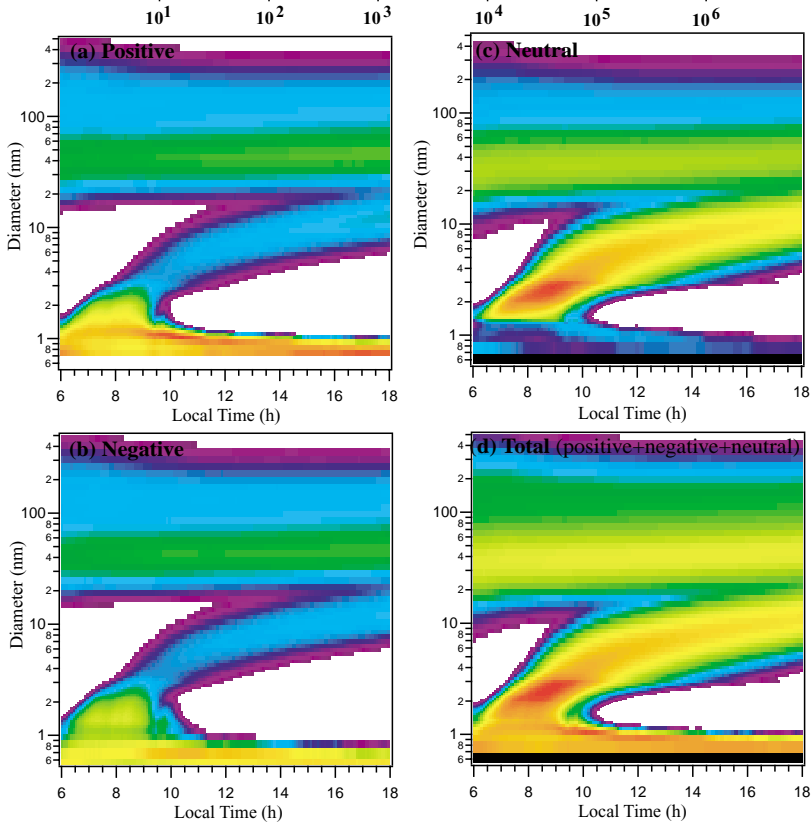

Fig. 9. Same as Fig. 4 except for the case study on 12 May 2005 (day 132). $\mathrm{CS}=1.0 \times 10^{-3} \mathrm{~s}^{-1}, \mathrm{C}_{\mathrm{COS}}^{\mathrm{peak}}=3 \times 10^{7} \mathrm{~cm}^{-3}$.

Most recently, Sipilä et al (2008) reported the existence of a pool of clusters smaller than $\sim 1.8-2 \mathrm{~nm}$ at night. These very small clusters $(<\sim 1.8 \mathrm{~nm})$ would logically be associated with ion-ion recombination clusters that are not activated, but have been stabilized at a sub-critical size by one or more unidentified species. Indeed, the general lack of sulfuric acid vapor at night poses a serious question as to how these nighttime TSCs are formed, and whether they have any relationship to daytime nucleation events. It is possible that species other than sulfuric acid (for example, certain organic compounds, nitric acid, ammonia, etc.) control the formation of sub- $1.8 \mathrm{~nm}$ clusters at night when the temperature is relatively lower, whereas sulfuric acid dominates nucleation during the day.

Based on IMN model simulations, all of the neutral particles between 1 and $3 \mathrm{~nm}$ in Figs. 4-9c are formed by the neutralization of charged particles. While activation and growth of these 1-3 nm neutral particles is the major source ( $>90 \%)$ of the predicted 3-nm particles, these seed particles originate from IMN rather than homogeneous nucleation. This is an important distinction: without ions, no 3-nm particles would be present in the simulations (again note the deep gap between $0.6 \mathrm{~nm}$ and $1 \mathrm{~nm}$ for neutral clusters in Fig.4-9c). Although all the new particles larger $3 \mathrm{~nm}$ in Figs. 4-9 are formed via IMN, only a small fraction of freshly nucleated particles around $3 \mathrm{~nm}$ are charged (further discussion on this point is given in Sect. 3.3 and 3.4).

\subsection{Charged fractions of freshly nucleated particles}

Simulated size-dependent charge fractions (CFs) at selected times for the eight case study days are shown in Fig. 10. The symbols (solid diamond) illustrated at a particle size of $3 \mathrm{~nm}$ correspond to observed CFs averaged over the nucleation periods obtained from Laakso et al. (2007a), and the symbols at $2 \mathrm{~nm}$ (asterisk) are the values backward calculated by Laakso et al. (2007a) using the " $\mathrm{K}$ " parameter derived by fitting the measured charged state of particles larger than $3 \mathrm{~nm}$. Laakso et al. (2007a) provided values of the charge state (S) for $2 \mathrm{~nm}$ particles and the corresponding "fitting" parameter K, which are used here to derive the original $\mathrm{S}$ values for $3 \mathrm{~nm}$ particles (the actual data). The data point in Fig. 10-d2 is from Atmos. Chem. Phys. Discuss. Version of Laakso et al. (2007a). We obtained the $\mathrm{CF}$ values for 2 and $3 \mathrm{~nm}$ particles shown in Fig. 10 by multiplying the derived $\mathrm{S}$ values by the corresponding model simulated average equilibrium charged fractions.

Figure 10 indicates that the IMN predicted size-dependent CFs are generally consistent - within a reasonable range of uncertainty - with the available observations on most of the days analyzed, in addition to the favorable agreement between simulated and observed $\mathrm{N}_{3-6}$ (see Fig. 3). According to the model, most of the clusters/particles $\sim 1.4 \mathrm{~nm}$ in diameter are negatively charged (up to $\sim 60-80 \%$ ), while most of those $\sim 1.1 \mathrm{~nm}$ are positively charged (up to $90 \%$ ). However, CFs decrease dramatically as particles grow beyond $\sim 1.5 \mathrm{~nm}$ owing to effective charge neutralization. Indeed, during the nucleation events illustrated, $\mathrm{CFs}$ achieve a minimum value of only $\sim 2-3 \%$ at particle diameters of $\sim 5 \mathrm{~nm}$. Particles larger than $\sim 5-7 \mathrm{~nm}$ are approximately in charge equilibrium with the background ion pool, where the predicted equilibrium CFs are consistent with measurements (Vana et al., 2006).

The agreement between simulated and observed CFs for freshly nucleated particles is poor for both positive and negative species on day 122 and for positive species on day 123 . The model simulations show that freshly nucleated particles on these two days should be significantly overcharged, both positively and negatively as well, but measurements indicate a weak overcharge for positive clusters on day 123 and significant undercharging on day 122 . One possible explanation for this difference is the involvement of species other than sulfuric acid in the overall nucleation process, which would not be treated in the IMN model. Another possible explanation is the inhomogeneity among the air masses sampled. It remains to be investigated how and to what degree air mass variability might lead to undercharging of 3-5 nm particles. One possible scenario is that many sub- $3 \mathrm{~nm}$ particles formed in locations favorable for nucleation but unfavorable for subsequent growth (relatively low T, high RH, low organics, such as over lakes) may be in closer equilibrium with ambient ions. When these sub- $3 \mathrm{~nm}$ particles are transported to locations favorable for growth (high condensable precursor 

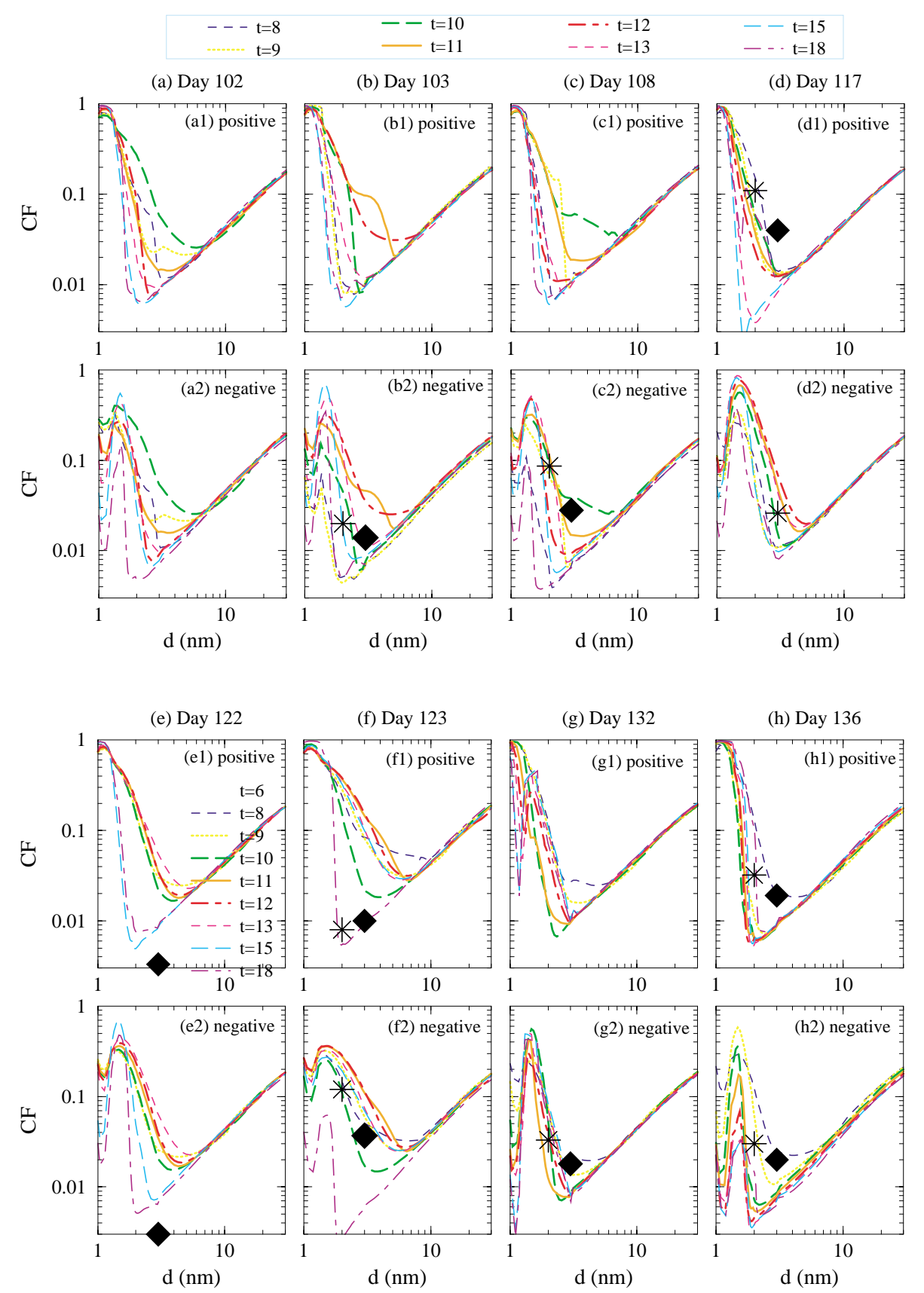

Fig. 10. IMN model predictions of size-dependent particle charge fractions (CFs) at selected local times (h) during the eight case study days. The symbols (solid diamonds) shown at $3 \mathrm{~nm}$ correspond to observed CFs averaged over specific nucleation periods as described by Laakso et al. (2007a), while the symbols (asterisks) at $2 \mathrm{~nm}$ are values inferred by Laakso et al. (2007a) using backward calculations from larger sizes. See the text for details.

gases, such as over forests), they may experience accelerated growth, leading to potential undercharging of particles in the $3-5 \mathrm{~nm}$ range. To resolve such scenarios, additional field data are needed so that air mass histories can be followed in more detail.
Following a more careful look at the time series of ionDMPS data for day 122 (unpublished data, L. Laakso, personnel communication), it appears that $3-5 \mathrm{~nm}$ particles are undercharged only during a roughly one-hour period corresponding to the high $\mathrm{N}_{3-6}$ spike on that day shown in Fig. 3g. On the other hand, freshly nucleated particles are actually highly negatively overcharged during other nucleation 
periods on the same day (122). The fact that the association of undercharging with the $\mathrm{N}_{3-6}$ spike for only a short period reinforces the idea that mixing of particles nucleated elsewhere may have contributed to the observed undercharging during that period on day 122 .

On day 123 , the IMN model predicts that freshly nucleated particles are significantly overcharged for both polarities. However, the ion-DMPS data given in Laakso et al. (2007a) indicate that freshly nucleated particles are significantly overcharged for the negative polarity only (see Fig. 10f). Such a difference, if real, may indicate that the IMN model over-predicts the positive ion nucleation on this day. It is noteworthy that, while the ion-DMPS data for day 123 show dramatic differences in the charged fractions of freshly nucleated particles of differing polarity, there exists much less difference in the concentrations of positively and negatively charged 2-4 nm particles as derived from Air Ion Spectrometer (AIS) and Balanced Scanning Mobility Analyzer (BSMA) measurements taken on the same day (unpublished data, Laakso, L., personnel communication). Based on these AIS and BSMA data, positive ions also appear to be substantially involved in the nucleation event on day 123 , which is in contrast with the ion-DMPS data, but consistent with IMN predictions.

The ion nucleation sign preference under atmospheric conditions is an important issue that requires further investigation. Apparently, in order to resolve the issue of an ambient nucleation charge preference, uncertainties in both kinetic modeling and field observations should be reduced. It has been pointed out in a number of studies that nucleation on negative ions is generally more favorable (Laakso et al., 2004b, 2007b; Wilhelm et al., 2004; Vana et al., 2006; Hirsikko et al., 2007; Winkler et al., 2008). Nevertheless, it should be emphasized that nucleation on positive ions frequently occurs in the atmosphere as well and can be dominant under some conditions. For example, observations show that the nucleation on positive ions may prevail in boreal forests on some days (Vana et al., 2006). Hirsikko et al. (2007) showed that, based on three years of measured size distributions of air ions $(0.42-7.5 \mathrm{~nm}$ in diameter), negative ions and positive ions were clearly involved in a total of 270 (26\% of the analyzed days) and 226 (22\% of the analyzed days) particle formation days, respectively. Based on the 7-week data record reported in Fig. 8 of Laakso et al. (2007a) and the one-year data record reported in Fig. 6 of Gagné et al. (2008), there does not seem to be a significant difference between positive and negative overcharging ratios for 3-5 nm particles, although negative overcharging ratios are much higher on a few days. It should be pointed out that in Fig. 7 of Laakso et al. (2007a), while the charging ratios for negative and positive $5 \mathrm{~nm}$ particles are similar, negative $3 \mathrm{~nm}$ particles have very high charging ratios while there is no data for positively charged $3 \mathrm{~nm}$ particles. Thus, it is not clear how differences in the detection efficiencies for positive and negative ions may affect the interpretation of these data.
In $\mathrm{Yu}$ (2006a), the possible reason for the sign preference is briefly discussed. The differences in the compositions and thermodynamic properties of positive and negative pre-nucleation clusters are considered in the kinetic model utilized by Yu (2006a), and in the present work. For the eight nucleation event days studied here, the IMN model predicts substantially more negative ion nucleation on day 117 (in terms of the average overcharging ratios for $3 \mathrm{~nm}$ particles, see the next section), and similar negative and positive ion nucleation on other days. Our model predictions are generally consistent with long-term measurements which indicate that both negative and positive ions are involved in most of the nucleation events detected in boreal forests, although nucleation on negative ions is slightly preferred on average. Of course, the IMN model has significant uncertainties, and many of the issues regarding charge preference are not settled. More detailed case studies, especially with regard to the time-dependent variations of the ion mobility spectrum and charging ratios derived from different instruments (BSMA, AIS, ion-DMPS), could help to identify and reduce the uncertainties.

\subsection{Overcharge ratios of freshly nucleated particles}

An aerosol immersed long enough in a steady-state ionplasma achieves an equilibrium charge distribution. For transient conditions, the ratio of an instantaneous $\mathrm{CF}$ to the equilibrium $\mathrm{CF}$ at the same size under similar ambient conditions is defined here as the overcharge ratio, OR. Figure 11 compares simulated and observed size-dependent OR values. The curves represent calculated OR values averaged over each nucleation period for the eight case study days, which show good overall agreement between simulated and observed concentrations and charged fractions of freshly nucleated particles in most cases. The open circles, on the other hand, define the range of observed OR values averaged over each nucleation event corresponding to about 30 nucleation events sampled with an ion-DMPS during spring 2005 in Hyytiälä, Finland, as a part of the BACCI/QUEST IV intensive field campaign (Laakso et al., 2007a). For most of the observations ( $>90 \%$ of events), freshly nucleated particles (3-4 nm) are overcharged (i.e., OR $>1$ ), which can only be explained by the contribution of ions to the nucleation process. Indeed, the IMN model predicts a rapid decrease in ORs as particle sizes increase from $\sim 2-3 \mathrm{~nm}$ to $\sim 5 \mathrm{~nm}$, in overall agreement with the measurements. Particles larger than $\sim 6 \mathrm{~nm}$ are slightly undercharged $(\mathrm{OR}<1)$ as a result of condensational growth owing to the fact that the equilibrium $\mathrm{CF}$ is increasing with particle size in this range. It is clear from the detailed kinetic IMN simulations that "measurable" overcharging would be limited to particles in the range of 3-5 nm, even when IMN is the only nucleation pathway that is active. The physics behind the rapid drop in ORs at small sizes is straightforward (Yu and Turco, 2007): charged clusters/particles nucleated on ions have a lifetime 

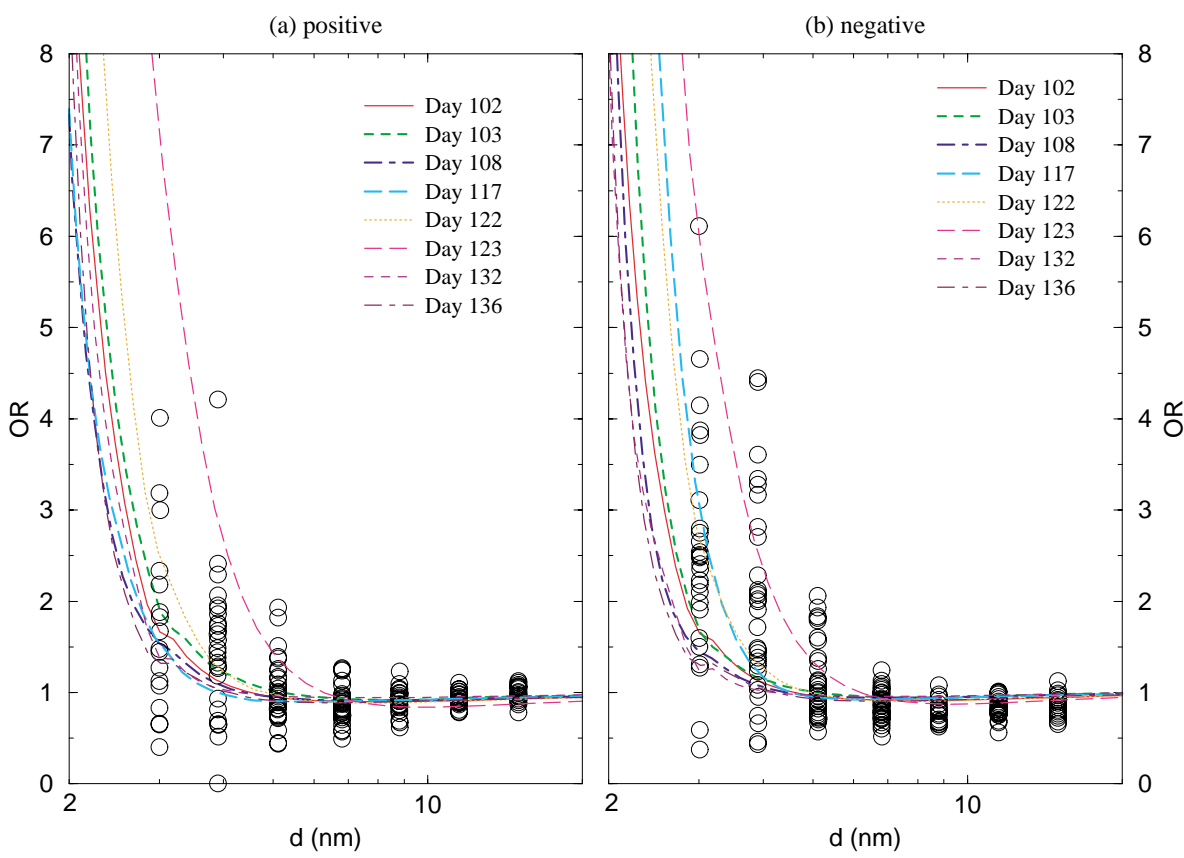

Fig. 11. IMN simulated and observed size-dependent overcharge ratios (OR). Each curve represents IMN model calculated OR values averaged over a nucleation event corresponding to a specific case study. The open circles are observed average OR values corresponding to roughly 30 nucleation events sampled with an ion-DMPS during spring 2005 in Hyytiälä, Finland, as a part of the BACCI/QUEST IV intensive field campaign (Laakso et al., 2007a).

of $\sim 0.3$ hour against neutralization by small ions/clusters of opposite charge, while it generally takes about $1-2 \mathrm{~h}$ for the same cluster to grow to $\sim 3 \mathrm{~nm}$, and another $1-2 \mathrm{~h}$ to grow to $\sim 5 \mathrm{~nm}$ under typical boreal forest conditions.

OR values for 3-5 $\mathrm{nm}$ particles depend strongly on the growth rate of sub- 3-5 nm particles (Yu and Turco, 2007; Kerminen et al., 2007). The large variations in the observed OR values for particles at given sizes $(3,4,5 \mathrm{~nm})$ on different days are likely to be associated with variations in the concentrations of the key precursor gases (sulfuric acid, and low volatility organics), and in the particle sizes at which organic vapors begin to condense (the activation sizes). The growth rate of sub-3-nm particles can be constrained by the time-delay between the increase in $\left[\mathrm{H}_{2} \mathrm{SO}_{4}\right]$ and $\mathrm{N}_{3-6}$ during the morning hours. As pointed out in Sect. 3.1, we assume that only sulfuric acid contributes to the growth of sub-3-nm particles since the condensation of $\mathrm{H}_{2} \mathrm{SO}_{4}$ (and associated water uptake) can, roughly speaking, fully explain the initial growth rates of sub-3-nm particles. While we believe that it is reasonable to assume a dominant contribution of $\mathrm{H}_{2} \mathrm{SO}_{4}$ (and associated water) to the growth of sub-3-nm particles, we acknowledge that it is quite possible that other materials (e.g., organics) may also contribute to the growth of sub-3$\mathrm{nm}$ particles under some conditions. Indeed, we have carried out sensitivity tests (not shown) in which $\mathrm{D}_{\text {act }}$ was decreased from $3 \mathrm{~nm}$ to $2.5 \mathrm{~nm}$ and then to $2 \mathrm{~nm}$, thus allowing "organic" condensation above these sizes. A value of $D_{\text {act }}$ of $2 \mathrm{~nm}$ greatly overestimated the growth rates of sub-3-nm particles, leading to simulated increases in $\mathrm{N}_{3-6}$ much too early compared to observations. However, the average ORs predicted for $D_{\text {act }}=2.5 \mathrm{~nm}$ and $2 \mathrm{~nm}$, while higher than those for $\mathrm{D}_{\mathrm{act}}=3 \mathrm{~nm}$, still fell within the range of observed average OR values shown in Fig. 11.

Figure 11 shows that observed OR values on most of the days ( $>\sim 80 \%)$ are within the range or above those predicted on the eight selected days. In other words, the observed OR values on most days ( $>280 \%)$ appears to support the dominance of IMN on those days. For the relatively few days $(<\sim 20 \%)$ where ORs are somewhat less than unity (undercharged) or close to unity (weakly overcharged), the simultaneous occurrence of homogeneous nucleation involving species other than sulfuric acid and water offers a possible explanation of the data. Unfortunately, there is currently no substantiated information regarding such species that might induce neutral homogeneous nucleation under boreal forest conditions. As was mentioned previously, both Janson et al. (2001) and Sellegri et al (2005a) concluded that the oxidation products of terpenes were not the actual nucleating species observed at Hyytiälä, Finland. Further, based on a kinetic $\mathrm{H}_{2} \mathrm{SO}_{4}-\mathrm{H}_{2} \mathrm{O}-\mathrm{NH}_{3}$ ternary homogeneous nucleation (THN) model constrained by laboratory measurements (Yu, 2006b), and a recently revised classical THN model (Merikanto et al., 2007), THN is expected to be negligible under the conditions encountered (see next section for more details). It should also be noted that the measurements reported in Riipinen et al. (2007) indicate that 
ammonia concentrations have no clear impact on observed particle formation rates. On the other hand, in accordance with the results for case study days 122 and 123 (Sect. 3.3), a weak overcharge or undercharge may also be associated with the significant variability in a particular air mass sampled, or uncertainty in the ion-DMPS measurements.

It should be noted that the one year of ion-DMPS data summarized in Fig. 6 of Gagné et al. (2008) are generally consistent with the 7-week ion-DMPS data shown in Fig. 8 of Laakso et al. (2007), both showing that a large fraction $(\sim 80 \%)$ of nucleation event days have clear overcharging of the $3-5 \mathrm{~nm}$ particles. The similar level and frequency of overcharging in other seasons (Gagné et al., 2008) may actually indicate that ion-mediated nucleation is significant at other times of the year as well.

3.5 Nucleation rates predicted based on different theories/models

Figure 12 illustrates the time-dependent variations of the instantaneous nucleation rates at the critical size $\left(J_{\text {crit }}\right)$, and the "apparent" nucleation rate defined as the appearance rate of 3-nm particles $\left(J_{3 \mathrm{~nm}}\right.$, which is typically observed) predicted with the present IMN model for the eight case study days discussed in Sect. 2. For comparison, we also show in Fig. 12 the equivalent predictions based on the Lovejoy et al. (2004) model ( $J_{\text {Lovejoy }}$, as parameterized by Modgil et al., 2005), kinetic quasi-unary nucleation model ( $J_{\mathrm{KQUN}}$, $\mathrm{Yu}, 2007)$, the empirical activation $\left(J_{\mathrm{act}}=A\left[\mathrm{H}_{2} \mathrm{SO}_{4}\right]\right.$ with $\left.A=2.4 \times 10^{-7} \mathrm{~s}^{-1}\right)$ and kinetic nucleation $\left(J_{\text {kin }}=K\left[\mathrm{H}_{2} \mathrm{SO}_{4}\right]^{2}\right.$ with $K=3.2 \times 10^{-14} \mathrm{~cm}^{3} \mathrm{~s}^{-1}$ ) formulas given in Riipinen et al. (2007), the kinetic ternary homogeneous nucleation (THN) model ( $\left.\mathrm{J}_{\mathrm{KTHN}}\right)$ of $\mathrm{Yu}(2006 \mathrm{~b})$, and revised classical THN model ( $\left.\mathrm{J}_{\mathrm{CTHN}}\right)$ of Merikanto et al. (2007).

The temporal variations of $J_{3 \mathrm{~nm}}$ presented in Fig. 12 are similar to those of simulated $\mathrm{N}_{3-6}$ shown in Fig. 3. This is not surprising inasmuch as $J_{3 \mathrm{~nm}}$ variations dominate the variations in $\mathrm{N}_{3-6}$, although $\mathrm{N}_{3-6}$ also depends on the loss rates of 3-6 nm particles as a result of coagulation with preexisting particles and growth out of the 3-6nm size range. Under the conditions studied here, the diameters of critical clusters generally range from $\sim 1.3 \mathrm{~nm}$ to $\sim 1.7 \mathrm{~nm}$ during the nucleation period. The time that $J_{3 \mathrm{~nm}}$ lags behind $J_{\text {crit }}$ varies owing to the diurnal changes in $\mathrm{H}_{2} \mathrm{SO}_{4}$ concentrations, and hence the growth rates of sub- $3 \mathrm{~nm}$ particles. The difference in the peak values of $J_{\text {crit }}$ and $J_{3 \mathrm{~nm}}$ depends on the growth rate and coagulation sink of sub- $3 \mathrm{~nm}$ particles.

As we have shown in previous sections, IMN model predictions capture the observed variation and magnitude of $\mathrm{N}_{3-6}$ (Fig. 3) as well as the general behavior of the measured overcharging ratio (Figs. 10 and 11) on most of case study days. It is clear from Fig. 12 that the model of Lovejoy et al. (2004) predicts negligible ion-induced nucleation on all days, and therefore appears to be inconsistent with the in situ observations of particle concentrations and over- charging (notwithstanding the occurrence of another undetermined nucleation source). The differences between $J_{\text {Lovejoy }}$ and $J_{\text {crit }}$ are more than 2-4 orders of magnitude and increase with the temperature. It is likely that the model of Lovejoy et al. (2004) under-predicts the contribution of ions to new particle formation in lower troposphere. The possible reasons for the difference between Lovejoy et al. (2004)'s model and our IMN model include different thermodynamic data used to represent the neutral $\mathrm{H}_{2} \mathrm{SO}_{4}-\mathrm{H}_{2} \mathrm{O}$ binary system, differences in the treatment of positive ions/clusters (the dynamics of positive ion clusters is not actually treated in Lovejoy et al.'s model), and different thermochemical data for ion clusters not directly investigated in the laboratory by Lovejoy et al., or for which alternative data exist (Yu, 2006a). It should be emphasized that the current version of the IMN model incorporates not only the thermodynamic data for small ion clusters used by Lovejoy et al. (2004), but also a number of other thermodynamic data sources and physically based schemes not considered by Lovejoy et al. (2004) (Yu, 2006a, 2007). Certainly, because of the sensitivity of nucleation rates to the thermodynamics of pre-nucleation clusters, further work is needed to reduce uncertainties in the thermodynamics parameters for these species. Nevertheless, simulations of the concentrations and size-resolved charged fractions of freshly formed particles representing most ( $>\sim 80 \%$ ) of nucleation event days measured in Hyytiälä appear to support the overall physical representations in the IMN model, although the reasons behind the difference between simulated and observed on the relatively few $(<\sim 20 \%)$ undercharged or weakly overcharged days remain unclear.

Under the conditions for the eight selected case study days, $\mathrm{H}_{2} \mathrm{SO}_{4}-\mathrm{H}_{2} \mathrm{O}$ binary homogeneous nucleation (BHN) rates were calculated with the recently developed quasi-unary nucleation model (Yu, 2007), which is constrained by multiple datasets. The predicted BHN rates (Fig. 12) all fall below $\sim 10^{-9}-10^{-11} \mathrm{~cm}^{-3} \mathrm{~s}^{-1}$, and thus are completely negligible. The ternary homogeneous nucleation rates are also negligible (well below $10^{-7} \mathrm{~cm}^{-3} \mathrm{~s}$ ) for all eight case study days, based on both the revised classical THN model of Merikanto et al. (2007) and the kinetic THN model of Yu (2006b). This is consistent with Riipinen et al.'s (2007) measurements indicating no obvious correlation between $\mathrm{NH}_{3}$ concentrations and nucleation rates.

Figure 12 also shows that the differences between $J_{\text {crit }}$ predicted by the IMN model and $J_{\text {act }}$ and $J_{\text {kin }}$ based on empirical formulas set out by Riipinen et al. (2007) can be relatively small in the early morning hours (i.e., $\sim 07: 00$ a.m. to $\sim$ 10:00 a.m.), but are much larger (by many orders of magnitude) at other times (especially near noon and afterwards). The empirical formulas predict much higher nucleation rates around noon because the sulfuric acid concentration is peaking near that time. However, this behavior is clearly inconsistent with observed decline in $\mathrm{N}_{3-6}$ in the afternoon (see Fig. 3 and also note the 1-2 $\mathrm{h}$ time delay between the nucleation rate and $\mathrm{N}_{3-6}$ ). By contrast, the IMN model captures 


$$
\begin{array}{llll}
\cdots-\cdots-J_{\text {crit }} & ----J_{\text {act }}=A\left[\mathrm{H}_{2} \mathrm{SO}_{4}\right] & ---J_{\text {Lovejoy }} & J_{\mathrm{CTHN}} \times 10^{6} \\
---J_{3 \mathrm{~nm}} & ---J_{\text {kin }}=K\left[\mathrm{H}_{2} \mathrm{SO}_{4}\right]^{2} & J_{\text {KQUN }} \times 10^{6} & \cdots
\end{array}
$$
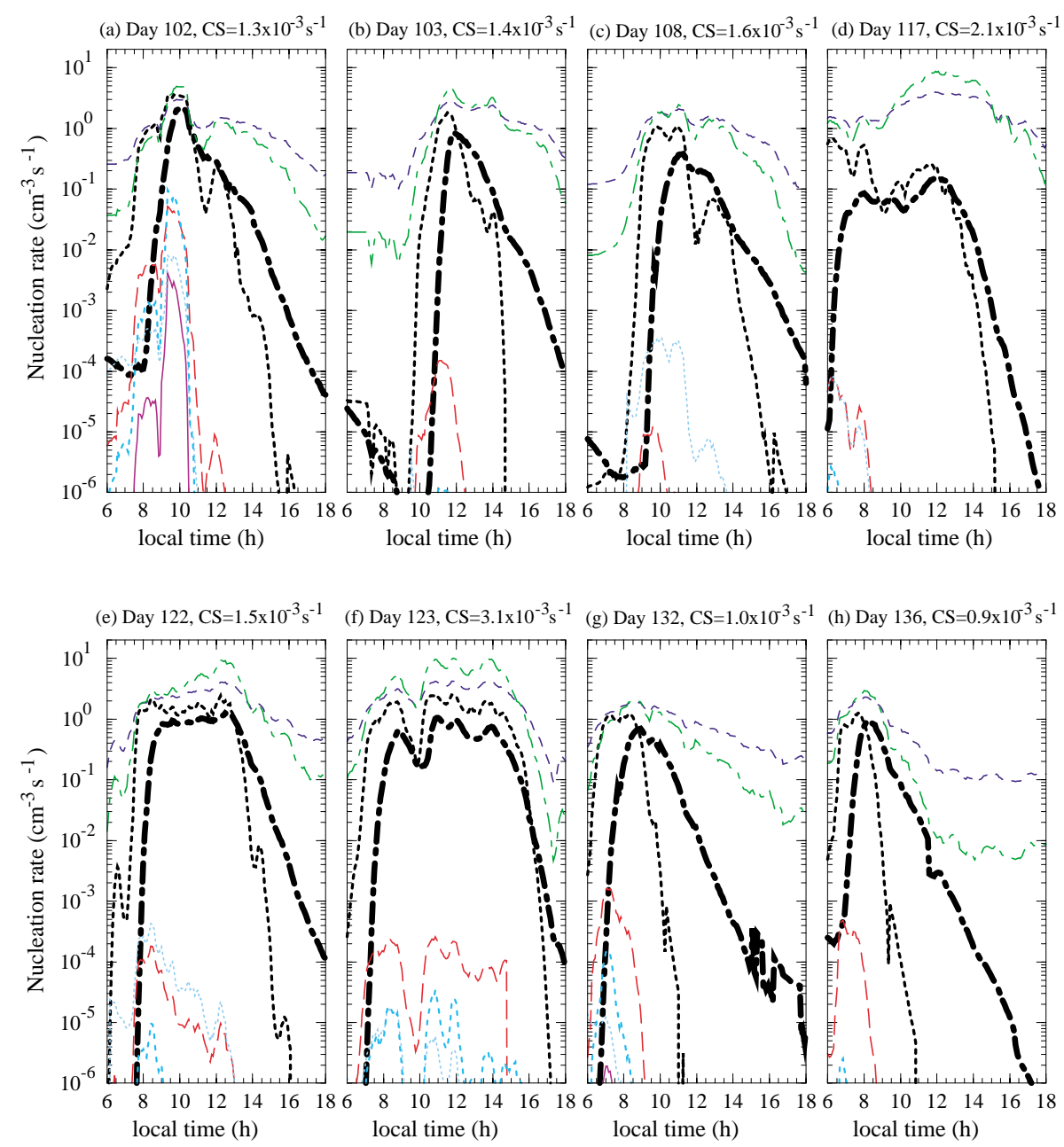

Fig. 12. IMN calculated time-dependent variations in nucleation rates based on model-simulated critical embryo sizes $\left(J_{\text {crit }}\right)$, and based on the production rate of 3-nm particles ( $J_{3 \mathrm{~nm}}$, the "apparent" nucleation rate typically observed). Results are given for each of the eight case studies discussed in Sect. 2. In each case, for comparison, predicted nucleation rates are shown for the ion nucleation model of Lovejoy

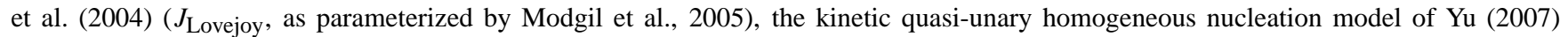
$\left(J_{\mathrm{KQUN}}\right)$, the empirical activation formula $\left(J_{\mathrm{act}}=A\left[\mathrm{H}_{2} \mathrm{SO}_{4}\right]\right.$ with $\left.A=2.4 \times 10^{-7} \mathrm{~s}^{-1}\right)$ and kinetic nucleation relationship $\left(J_{\mathrm{kin}}=K\left[\mathrm{H}_{2} \mathrm{SO}_{4}\right]^{2}\right.$ with $K=3.2 \times 10^{-14} \mathrm{~cm}^{3} \mathrm{~s}^{-1}$ ) proposed by Riipinen et al. (2007), the kinetic ternary homogeneous nucleation (THN) model ( $\left.J_{\mathrm{KTHN}}\right)$ of $\mathrm{Yu}(2006 \mathrm{~b})$, and revised classical THN model ( $\left.J_{\mathrm{CTHN}}\right)$ of Merikanto et al. (2007) (ammonia mixing ratio of $1000 \mathrm{ppt}$ assumed). Note that the $J_{\mathrm{KQUN}}, J_{\mathrm{KTHN}}$, and $J_{\mathrm{CTHN}}$ curves indicated in the figures represent the corresponding values multiplied by a factor of $10^{6}$.

the fall-off in $\mathrm{N}_{3-6}$ quite well (accounting for uncertainties in the growth rate of 3-6 $\mathrm{nm}$ particles associated with organic condensation, as noted earlier). An analysis of the IMN simulations indicates that the main factors limiting nucleation (and hence the concentrations of 3-6 nm particles) after midday are the higher temperatures and lower relative humidities typical of those times of the day (Fig. 2), which inhibit the formation of TSCs via IMN. It should be noted that the empirical activation and kinetic nucleation formula (i.e., $J_{\text {act }}$ and $J_{\text {kin }}$ ) are regression parameterizations which do not aim to describe detailed physics.

\section{Summary and discussion}

The unique long-term and multiple-instrument characterizations of nucleation events obtained at a boreal forest site (Hyytiälä, Finland) by Kulmala and colleagues provide the most comprehensive set of data available to date to test nucleation theories of atmospheric particle formation. While the measurements of ion mobility and charged fractions of freshly nucleated particles at that site indicate that ions are involved in more than $90 \%$ of the clearly identified particle formation events, the relative contributions of ion-mediated 
nucleation versus neutral processes has remained unresolved. In part, this lack of resolution may be due to the fact that, even when the same sets of measurements are considered, different groups have used dramatically different analytical approaches. A comprehensive study of the latest multiparameter observations has therefore been carried out to shed new light on atmospheric particle nucleation mechanisms. For this purpose, we performed detailed case studies of representative and well-defined nucleation events observed during the BACCI/QUEST IV intensive field campaign in spring 2005 in Hyytiälä, Finland, utilizing the kinetic Ion-Mediated Nucleation (IMN) model developed over the last decade. Appropriate sensitivity studies were also designed to investigate the effect of the variations in important parameters, such as the condensation sink and precursor gas concentrations, on the simulated results.

From 22 days during which nucleation events occurred during the 42 days of the BACCI/QUEST IV intensive field campaign, we selected 8 days for the present study based on indications that the sampled air masses were relatively homogeneous (in term of well-defined and consistent diurnal variations in measured $\left[\mathrm{H}_{2} \mathrm{SO}_{4}\right]$ and $\mathrm{N}_{3-6}$ ). These selected case study days are representative of the ranges of $\left[\mathrm{H}_{2} \mathrm{SO}_{4}\right]$ and $\mathrm{N}_{3-6}$, as well as the charged fractions of freshly nucleated particles, encountered over time at this site.

For most of days studied, the IMN model provides reasonable agreement between observed and predicted diurnal variations in the concentrations of freshly nucleated particles in the $3-6 \mathrm{~nm}$ size range (including the timing of the particle concentration increase, peak concentrations, and the rate of decrease following the peak). Likewise, good agreement was found between measured and calculated average particle charge fractions. On all the case study days considered, the predicted average diameter of $\sim 1.5 \mathrm{~nm}$ for critical cluster activation during nucleation periods is supported by recent measurements in a boreal forest setting (Kulmala et al., 2007). Further, the simulated presence of several thousands $\left(\right.$ per $\mathrm{cm}^{3}$ ) of $1.8-3 \mathrm{~nm}$ thermodynamically stable clusters (TSCs) during such nucleation events is remarkably consistent with the typical concentrations of $1.8-3 \mathrm{~nm}$ particles detected in boreal forests, as reported by Kulmala et al. (2007). The predicted strong diurnal variation in these $1.8-3 \mathrm{~nm}$ particles is generally consistent with AIS, BSMA, NAIS-positive and UF0-02proto CPC pair data presented in Kumala et al. (2007), although apparently in conflict with the NAIS-negative measurements reported in Kulmala et al. (2007). We note that the resolution of differences between observations and simulations of the diurnal variation in the $1.8-3 \mathrm{~nm}$ particle concentration may have significant implications regarding competing nucleation theories.

A comparison of simulated average size-dependent values of the overcharging ratio (OR) with measured values corresponding to about 30 nucleation events sampled during spring 2005 in Hyytiälä shows that observed ORs for most days ( $>80 \%$ ) are within the range of, or exceed, those pre- dicted by the IMN model. It is reasonable to conclude that the observed OR values mainly appear to support the significance of IMN on most days. This conclusion is further supported by the overall agreement between the simulated and observed properties and behavior of nucleation events and multiple observational parameters (including critical nucleation cluster sizes, size-dependent nanoparticle overcharging ratios, concentrations of sub-3 nm stable nuclei and 3-6 nm neutral particles, and their diurnal variations) on such days. It should be noted that, while our specific results indicate a dominant role for IMN, we clearly acknowledge the possibility that other nucleation sources, which have not been sufficiently quantified up to this point, may in fact be significant in the face of remaining uncertainties in the modeling and field observations.

On several of case study days, for example, we find large differences in the timing of $\mathrm{N}_{3-6}$ increase and charging states. Also, the IMN model cannot directly explain the $\sim 20 \%$ of nucleation event days with weak overcharging or weak undercharging (although the non-local formation of thermodynamically stable clusters, or TSCs, via ion-ion recombination may play a role). Based on sensitivity tests and analyses of unpublished data made available to us during the review of this paper, we tentatively conclude that some of differences on the relatively few days where differences are most significant may be associated with: (1) the possible role of species other than sulfuric acid in the nucleation process (i.e., yet to be identified neutral nucleation mechanisms); (2) the large variability in the related air masses sampled with stationary instruments; and (3) uncertainties in measurements, both in the field observations and laboratory data underlying the kinetic modeling. We also emphasize that presently no alternative quantitative nucleation mechanism is capable of explaining nucleation events observed in boreal forests. Measurements appear to indicate that organic species are not involved in the early stages of such events, and that ammonia has no clear effect on observed particle formation rates in boreal forests.

The time-dependent nucleation rates predicted with the current IMN model for the eight case study days have been compared with values derived using a number of other nucleation models or parameterizations. The calculated binary and ternary homogeneous nucleation rates based on recently updated or revised models fall well below $\sim 10^{-7} \mathrm{~cm}^{-3} \mathrm{~s}^{-1}$, and thus cannot explain the observed nucleation events. Compared to the values predicted by IMN model, which are consistent with a variety of measurements as noted above, the nucleation rates predicted by the Lovejoy et al. (2004) ion nucleation model are lower by more than 2-4 orders of magnitude, with the difference becoming larger at higher temperatures. It appears that the ion nucleation model originally developed by Lovejoy et al. (2004) significantly under-predicts ion nucleation rates, and cannot explain the new observations from Hyytiälä regarding the electrical properties of nanoparticles. The differences between the nucleation rates predicted 
by the IMN model and those based on empirical formulas advanced by Riipinen et al. (2007) are very large at most times of the day. The difference is not surprising as these empirical relations are derived from statistical regressions that do not aim to describe detailed physics, yielding prefactor constants that have a wide range of values for different times and locations.

Obviously, uncertainties remain in both the IMN model parameterizations and in the measured properties of freshly nucleated particles under a range of atmospheric conditions. Additional case studies to investigate specific nucleation events that are well defined observationally would build confidence in existing nucleation theories. Comparisons of simulated and observed time series of overcharging ratios on selected days may provide additional information and insight. It is also necessary to extend field measurement capabilities to smaller particle sizes, with accurate resolution of native electrical charge and composition, to constrain models and differentiate between competing mechanisms. It is clear from this discussion that sampling within homogeneous air masses is critical, and Lagrangian sampling of specific air parcels would be even more favorable for detailed nucleation analysis. Likewise, direct laboratory and computational studies of the properties of nucleation-sized molecular clusters, and measurements of nucleation rates under controlled conditions, represent an important element of an overall strategy to bring the science of atmospheric particle formation to a level of precision adequate for supporting advanced climate, air quality and health assessments.

Acknowledgements. The authors thank M. Kulmala and colleagues for inviting F. Yu to visit the University of Helsinki during the revision of this paper, and allowing us to access and use some of their unpublished data. Special thanks are extended to L. Laakso, I. Riipinen, S. Gagne, T. Nieminen, and V. Kerminen for useful discussions and assistance during the visit. The critical and constructive comments of two anonymous referees leading to improvements to this paper are also acknowledged. The research was supported by the NSF under grant 0618124 and NOAA/DOC under grant NA05OAR4310103.

Edited by: M. Kulmala

\section{References}

Dal Maso, M., Kulmala, M., Riipinen, I., Wagner, R., Hussein, T., Aalto, P. P., and Lehtinen, K. E. J.: Formation and growth of fresh atmospheric aerosols: eight years of aerosol size distribution data from SMEAR II, Hyytiälä, Finland, Boreal Env. Res., 10, 323 336, 2005.

Ehn, M., Petj, T., Aufmhoff, H., Aalto, P., Hmeri, K., Arnold, F., Laaksonen, A., and Kulmala, M.: Hygroscopic properties of ultrafine aerosol particles in the boreal forest: diurnal variation, solubility and the influence of sulfuric acid, Atmos. Chem. Phys., 7, 211-222, 2007,

http://www.atmos-chem-phys.net/7/211/2007/.
Engelhart, G. J., Asa-Awuku, A., Nenes, A., and Pandis, S. N.: CCN activity and droplet growth kinetics of fresh and aged monoterpene secondary organic aerosol, Atmos. Chem. Phys., 8, 3937-3949, 2008, http://www.atmos-chem-phys.net/8/3937/2008/.

Gagné, S., Laakso, L., Petäjä, T., Kerminen, V.-M., and Kulmala, M.: Analysis of one year of Ion-DMPS data from the SMEAR II station, Finland, Tellus B, 60(3), 318-329, 2008.

Hanson, D. R. and Eisele, F.: Diffusion of $\mathrm{H}_{2} \mathrm{SO}_{4}$ in Humidified Nitrogen: Hydrated $\mathrm{H}_{2} \mathrm{SO}_{4}$, J. Phys. Chem. A, 104(8), 17151719, 2000.

Hanson, D. R. and Lovejoy, E. R.: Measurement of the thermodynamics of the hydrated dimer and trimer of sulfuric acid, J. Phys. Chem. A, 110, 9525-9528, doi:10.1021/jp062844w, 2006.

Hirsikko, A., Bergman, T., Laakso, L., Dal Maso, M., Riipinen, I., Hõrrak, U., and Kulmala, M.: Identification and classification of the formation of intermediate ions measured in boreal forest, Atmos. Chem. Phys., 7, 201-210, 2007, http://www.atmos-chem-phys.net/7/201/2007/.

Iida, K., Stolzenburg, M., McMurry, P., Dunn, M. J., Smith, J. N., Eisele, F., and Keady, P.: Contribution of ion-induced nucleation to new particle formation: Methodology and its application to atmospheric observations in Boulder, Colorado, J. Geophys. Res., 111, D23201, doi:10.1029/2006JD007167, 2006.

Janson, R., Rosman, K., Karlsson, A., and Hansson, H. C.: Biogenic emissions and gaseous precursors to forest aerosols, Tellus B, 53, 423-440, 2001.

Kazil, J., Lovejoy, E. R., Jensen, E. J., and Hanson, D. R.: Is aerosol formation in cirrus clouds possible?, Atmos. Chem. Phys., 7, 1407-1413, 2007, http://www.atmos-chem-phys.net/7/1407/2007/.

Kerminen, V.-M., Anttila, T., Petäjä, T., Laakso, L., Gagné, S., Lehtinen, K. E. J., and Kulmala, M.: Charging state of the atmospheric nucleation mode: Implications for separating neutral and ion-induced nucleation, J. Geophys. Res., 112, D21205, doi:10.1029/2007JD008649, 2007.

Kulmala, M., Riipinen, I., Sipilä, M., et al.: Toward direct measurement of atmospheric nucleation, Science, 318, 89-92, 2007.

Kulmala, M., Vehkamaki, H., Petaja, T., Dal Maso, M., Lauri, A., Kerminen, V.-M., Birmili, W., and McMurry, P. H.: Formation and growth rates of ultrafine atmospheric particles: A review of observations, J. Aerosol Sci., 35, 143-176, 2004a.

Kulmala, M., Laakso, L., Lehtinen, K. E. J., Riipinen, I., Dal Maso, M., Anttila, T., Kerminen, V.-M., Hrrak, U., Vana, M., and Tammet, H.: Initial steps of aerosol growth, Atmos. Chem. Phys., 4, 2553-2560, 2004, http://www.atmos-chem-phys.net/4/2553/2004/.

Kulmala, M., Kerminen, V.-M., Anttila, T., Laaksonen, A., and O'Dowd, C. D., Organic aerosol formation via sulphate cluster activation. J. Geophys. Res. 109, D04205, doi:10.1029/2003JD003961, 2004c.

Kulmala, M., Pirjola, L., and Makela, J.: Stable sulphate clusters as a source of new atmospheric particles, Nature, 404, 66-69, 2000.

Laakso, L., Gagné, S., Petäjä, T., Hirsikko, A., Aalto, P. P., Kulmala, M., and Kerminen, V.-M.: Detecting charging state of ultra-fine particles: instrumental development and ambient measurements, Atmos. Chem. Phys., 7, 1333-1345, 2007, http://www.atmos-chem-phys.net/7/1333/2007/.

Laakso, L., Grönholm, T., Kulmala, L., et. al.: Hot-air balloon as a 
platform for boundary layer profile measurements during particle formation, Boreal Env. Res., 12, 279-294, 2007b.

Laakso, L., Petäjä, T., Lehtinen, K. E. J., Kulmala, M., Paatero, J., Hõrrak, U., Tammet, H., and Joutsensaari, J.: Ion production rate in a boreal forest based on ion, particle and radiation measurements, Atmos. Chem. Phys., 4, 1933-1943, 2004a, http://www.atmos-chem-phys.net/4/1933/2004/.

Laakso, L., Anttila, T., Lehtinen, K. E. J., Aalto, P. P., Kulmala, M., Hõrrak, U., Paatero, J., Hanke, M., and Arnold, F.: Kinetic nucleation and ions in boreal forest particle formation events, Atmos. Chem. Phys., 4, 2353-2366, 2004,

http://www.atmos-chem-phys.net/4/2353/2004/.

Laaksonen, A., Kulmala, M., O’Dowd, C. D., Joutsensaari, J., Vaattovaara, P., Mikkonen, S., Lehtinen, K. E. J., Sogacheva, L., Dal Maso, M., Aalto, P., Petäjä, T., Sogachev, A., Yoon, Y. J., Lihavainen, H., Nilsson, D., Facchini, M. C., Cavalli, F., Fuzzi, S., Hoffmann, T., Arnold, F., Hanke, M., Sellegri, K., Umann, B., Junkermann, W., Coe, H., Allan, J. D., Alfarra, M. R., Worsnop, D. R., Riekkola, M. -L., Hyötyläinen, T., and Viisanen, Y.: The role of VOC oxidation products in continental new particle formation, Atmos. Chem. Phys., 8, 2657-2665, 2008, http://www.atmos-chem-phys.net/8/2657/2008/.

Lovejoy, E. R., Curtius, J., and Froyd, K. D.: Atmospheric ioninduced nucleation of sulfuric acid and water, J. Geophys. Res., 109, D08204, doi:10.1029/2003JD004460, 2004.

Marti, J. J., Jefferson, A., Ping Cai, X., Richert, C., McMurry, P. $\mathrm{H}$., and Eisele, F.: $\mathrm{H}_{2} \mathrm{SO}_{4}$ vapor pressure of sulfuric acid and ammonium sulfate solutions, J. Geophys. Res., 102(D3), 37253736, 1997.

Modgil, M. S., Kumar, S., Tripathi, S. N., and Lovejoy, E. R.: A parameterization of ion-induced nucleation of sulphuric acid and water for atmospheric conditions, J. Geophys. Res., 110, D19205, doi:10.1029/2004JD005475, 2005.

Nadykto, A. B. and Yu, F.: Strong hydrogen bonding between atmospheric nucleation precursors and organic acids, Chem. Phys. Lett., 435, 14-18, 2006.

O’Dowd, C. D., Yoon, Y. J., Junkerman, W., Aalto, P., Kulmala, M., Lihavainen, H., and Viisanen, Y.: Airborne measurements of nucleation mode particles II: boreal forest nucleation events, Atmos. Chem. Phys. Discuss., 8, 2821-2848, 2008, http://www.atmos-chem-phys-discuss.net/8/2821/2008/.

Riipinen, I., Sihto, S.-L., Kulmala, M., Arnold, F., Dal Maso, M., Birmili, W., Saarnio, K., Teinilä, K., Kerminen, V.-M., Laaksonen, A., and Lehtinen, K. E. J.: Connections between atmospheric sulphuric acid and new particle formation during QUEST III-IV campaigns in Heidelberg and Hyytiälä, Atmos. Chem. Phys., 7, 1899-1914, 2007, http://www.atmos-chem-phys.net/7/1899/2007/.

Sellegri, K., Umann, B., Hanke, M., and Arnold, F.: Deployment of a ground-based CIMS apparatus for the detection of organic gases in the boreal forest during the QUEST campaign, Atmos. Chem. Phys., 5, 357-372, 2005, http://www.atmos-chem-phys.net/5/357/2005/.
Sellegri, K., Hanke, M., Umann, B., Arnold, F., and Kulmala, M.: Measurements of organic gases during aerosol formation events in the boreal forest atmosphere during QUEST, Atmos. Chem. Phys., 5, 373-384, 2005, http://www.atmos-chem-phys.net/5/373/2005/.

Sipilä, M., Lehtipalo, K., Kulmala, M., Petäjä, T., Junninen, H., Aalto, P. P., Manninen, H. E., Vartiainen, E., Riipinen, I., Kyrö, E.-M., Curtius, J., Kürten, A., Borrmann, S., and O'Dowd, C. D.: Applicability of condensation particle counters to measure atmospheric clusters, Atmos. Chem. Phys., 8, 4049-4060, 2008, http://www.atmos-chem-phys.net/8/4049/2008/.

Vana, M., Tamm, E., Hõrrak, U., Mirme, A., Tammet, H., Laakso, L., Aalto, P. P., and Kulmala, M.: Charging state of nanoparticles during the nucleation burst events, Atmos. Res., 82, 536-546, 2006.

Wilhelm, S., Eichkorn, S., Wiedner, D., Pirjola, L. and Arnold, F.: Ion-induced aerosol formation: new insights from laboratory measurements of mixed cluster ions, $\mathrm{HSO}_{4}^{-}\left(\mathrm{H}_{2} \mathrm{SO}_{4}\right)_{a}\left(\mathrm{H}_{2} \mathrm{O}\right)_{w}$ and $\mathrm{H}^{+}\left(\mathrm{H}_{2} \mathrm{SO}_{4}\right)_{a}\left(\mathrm{H}_{2} \mathrm{O}\right)_{w}$, Atmos. Environ., 38, 1735-1744, 2004.

Winkler, P. M., Steiner, G., Vrtala, A., Vehkamaki, H., Noppel, M., Lehtinen, K. E. J., Reischl, G. P., Wagner, P. E., and Kulmala, M.: Heterogeneous Nucleation Experiments Bridging the Scale from Molecular Ion Clusters to Nanoparticles, Science, 319, 1374 1377, 2008

Yu, F.: From molecular clusters to nanoparticles: Secondgeneration ion-mediated nucleation model, Atmos. Chem. Phys., 6, 5193-5211, 2006a, http://www.atmos-chem-phys.net/6/5193/2006/.

Yu, F.: Effect of ammonia on new particle formation: A kinetic $\mathrm{H}_{2} \mathrm{SO}_{4}-\mathrm{H}_{2} \mathrm{O}-\mathrm{NH}_{3}$ nucleation model constrained by laboratory measurements, J. Geophys. Res., 111, D01204, doi:10.1029/2005JD005968, 2006b.

Yu, F.: An improved quasi-unary nucleation model for binary $\mathrm{H}_{2} \mathrm{SO}_{4}-\mathrm{H}_{2} \mathrm{O}$ homogeneous nucleation, J. Chem. Phys., 127, 054301, 2007.

Yu, F. and Turcom R. P.: The role of ions in the formation and evolution of particles in aircraft plumes, Geophys. Res. Lett., 24, 1927-1930, 1997.

Yu, F. and Turcom R. P.: Ultrafine aerosol formation via ionmediated nucleation, Geophys. Res. Lett., 27, 883-886, 2000.

Yu, F. and Turco, R. P.: From molecular clusters to nanoparticles: The role of ambient ionization in tropospheric aerosol formation, J. Geophys. Res., 106, 4797-4814, 2001.

Yu, F. and Turco, R. P.: Charging State of Freshly Nucleated Particles: Implication for Nucleation Mechanisms, in Proceeding of 17th International Conference on Nucleation Atmospheric Aerosols, Galway, Ireland, 13-17 August, 392-395, 2007.

Yu, F., Wang, Z., Luo, G., and Turco, R. P.: Ion-mediated nucleation as an important source of tropospheric aerosols, Atmos. Chem. Phys., 8, 2537-2554, 2008, http://www.atmos-chem-phys.net/8/2537/2008/. 